\title{
Molecular Basis of Physical and Chemical Probes for Spindle Assembly
}

\author{
Hidemi Sato*, Akio Kobayashi** and Tomohiko J. Itoh*; *** \\ ${ }^{*}$ Sugashima Marine Biological Laboratory, Nagoya University, Toba, Mie 517, \\ and ${ }^{* *}$ Department of Agricultural Chemistry, Okayama University, Okayama \\ 700. Japan
}

\begin{abstract}
Microtubules are major cytoskeletal components of the mitotic spindles in echinoderm eggs. Well preserved isolated spindles from the first cleavage of sea urchin eggs reveal that 3,000 to 5,000 orderly arranged microtubules are present. Considering the sensitive nature of spindle birefringence, it is highly probable that the spindle assembly is regulated by the labile association of tubulin molecules and the involvement of kinetic centers such as the kinetochores and MTOCs in the centrosome region.

Heavy water $\left(\mathrm{D}_{2} \mathrm{O}\right)$ increases the spindle volume and birefringence in living and dividing sea urchin eggs. Through the in vitro experiments, we confirmed that the initial rate and the final extent of polymerization of both bovine brain tubulin and sea urchin egg tubulin were enhanced in the presence of $\mathrm{D}_{2} \mathrm{O}$. Yields were higher as the $\mathrm{D}_{2} \mathrm{O}$ concentration increased. $\mathrm{D}_{2} \mathrm{O}$ also reduced the critical concentration for polymerization of brain tubulin. Thermodynamic analysis was attempted using the temperature dependence of the critical concentration in the presence of $\mathrm{D}_{2} \mathrm{O}$. We obtained linear van't Hoff plots and calculated thermodynamic parameters which were positive and increased with the elevation of the $\mathrm{D}_{2} \mathrm{O}$ concentration. The enhancement of the polymerization of tubulin by $\mathrm{D}_{2} \mathrm{O}$ in vitro could, therefore, be the result of the strengthening of intra- and/or inter-molecular hydrophobic interactions of tubulin molecules. We believe that the increase in length and number of microtubules of the mitotic spindles in dividing cells of eukaryotes with $\mathrm{D}_{2} \mathrm{O}$ is caused by the direct involvement of $\mathrm{D}_{2} \mathrm{O}$ in the polymerization of tubulin.

When fertilized sea urchin eggs were exposed to dilute solutions of alkylresorcinols, i.e. T-1, an isolate from the culture medium of Pseudomonas sp., its derivatives or analogs such as Ansamycin, Curvularin or Macbecin I, spindles were more or less arrested in metaphase and became either barrel-shaped or extremely enhanced. T-1 and Curvularin, which induced barrel-shaped spindles, possessed the same structural features with respect to 1,3-benzenediol system with long lipophilic side chains. Structural modification of one of the hydroxyl groups of Curvularin provides a remarkable increase in chemical efficacy. This effect can be considered to be a freezing of the state of dynamic equilibrium or partial association/dissociation of tubulin molecules along with the microtubules by the given drugs. The barrel-shaped spindles consisted of bundles of straight microtubules of equal length, and we believe this might
\end{abstract}

\footnotetext{
*** Present adress of Dr. Itoh is: Exploratory Research for Advanced Technology, Research Development Corporation of Japan, Hotani Molecular Dynamic Assembly Project, 15 Morimoto-cho, Shimogamo, Sakyo-ku, Kyoto, 606
} 
reflect the stabilized state of tubulin polymers caused by the local increase of molecular hydrophobicity. The anaphase sequence was usually delayed and chromosomes moved very slowly. We found that this unusual spindle shape was induced by the spread, discoidal redistribution of centrosomal MTOCs, and comparable with the irregular sea urchin spindles induced with mercaptoethanol.

The finding of the TO series compounds turned our attention to 1,4-benzoquinones with long hydrophilic side chains, and Macbecin I was recognized to be a unique mitotic arrester. This compound could be a lead compound to search new mitotic arresters and its analogues obtained by synthesis. The unique in vivo assay system developed by us using the mitosis in dividing sea urchin eggs can be widely applied for the experimental survey of new mitotic arresters. Further massive screening effort would provide us more opportunity to find new drugs which can be used as the molecular probes to analyze the physicochemical basis of the assembly and/or disassembly of cytoskeleton.

\section{INTRODUCTION}

The mitotic spindle (Fig. 1C) is a cellular organelle newly assembled in a eukaryote at mitosis and disassembled after the completion of cell division. The major function is to orient and align replicated chromosomes, then to transport chromosomes into two daughter cells. The inner structure of the living mitotic spindle is difficult to visualize with phase-contrast or differential interference microscopy due to the minute difference in the refractive indices encountered (Fig. 1A). However, owing to the optical anisotropy of the spindle fine structure, we can visualize the fibrous components of the spindle under a sensitive polarizing microscope (Fig. 1B). This optical anisotropy or the birefringence could reflect the amount of orderly aligned fibrous structure within the spindle $(13,49)$. Various conditions and agents have been tested that systematically and reversibly alter spindle morphology and birefringence. From a series of observations and experiments (1, $13,14,48,57)$, we postulated that spindle fibers are composed mainly of parallel arrays of microtubules formed by a reversible association of tubulin molecules, and there exists a dynamic equilibrium between the labile spindle fibers and a pool of unassociated tubulin (13). The assembly of microtubules is more than likely controlled by kinetic centers such as centrosomes, MTOCs and kinetochores, and the available concentration of polymerizable tubulin dimers. Hill and Chen (1984) suggested the possible phase changes at the end of microtubule with GTP cap in vitro system, and Farrel et al. (1987) described the phase dynamics at microtubule ends, and postulated that microtubules in cell may have an inherent tendency to remain in the polymerized state, and the microtubule disassembly must be induced actively.

At present, we have many standing hypotheses to interprete the spindle assembly

Fig. 1. Mitosis observed in various organism with different optics. A. The mitosis observed in the dividing endosperm of Haemanthus katherinae. A phase contrast microscopy shows no detectable spindle structure except clearly contrasted chromosomes. B. Mitosis in the dividing endosperm of Haemanthus albiflos. Chromosomal spindle fibers can clearly be observed under the sensitive polarizing microscope owing to their birefringent nature. C. Mitosis in a dividing white fish blastomere that has been fixed, sectioned and stained with Haematoxylin and Eosin. D. Mitotic apparatus isolated from the mature oocyte of star fish, Pisaster ochraceus. Polarizing microscope revealed the birefringent spindle structure (50). 

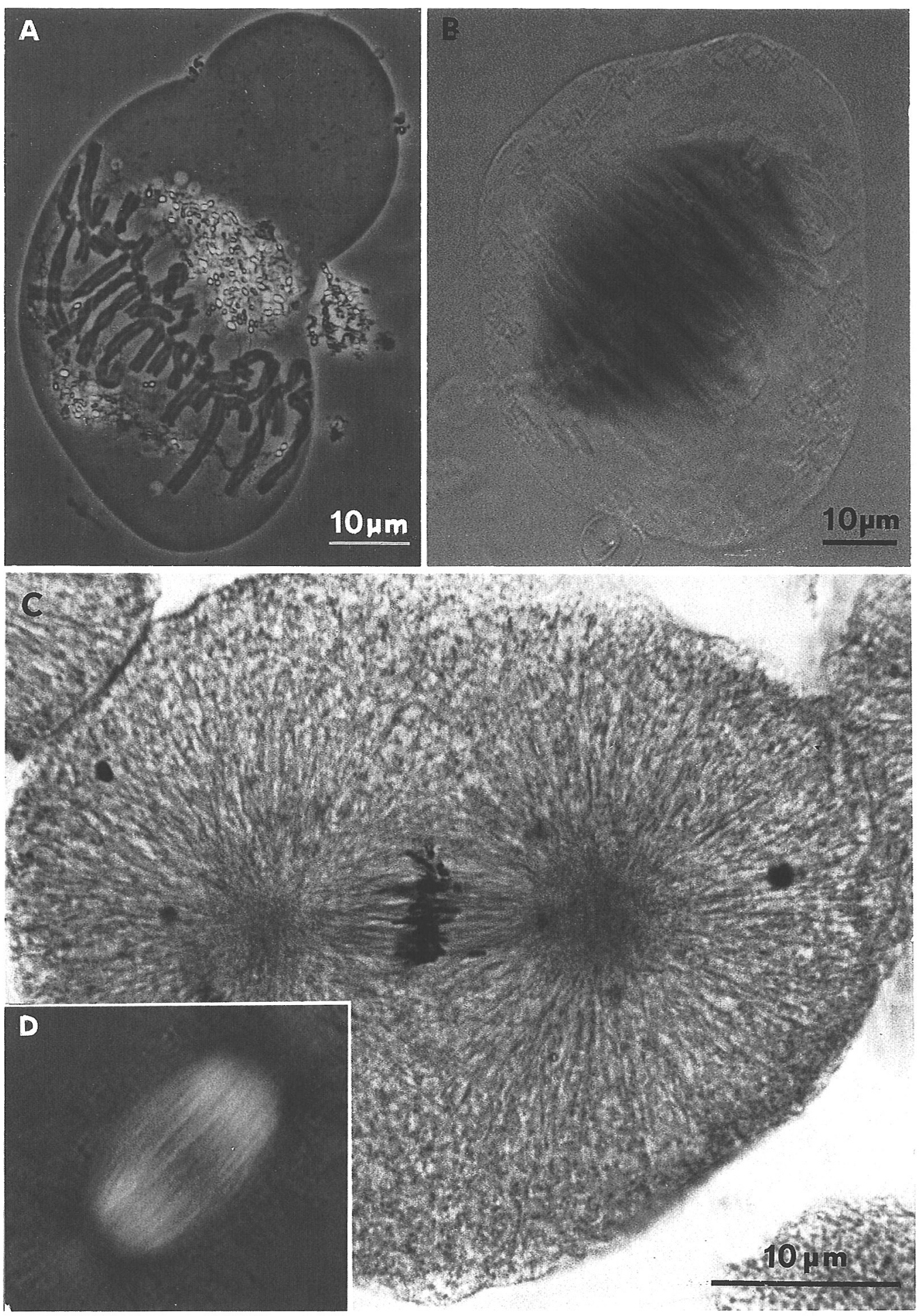
and the anaphase chromosome movement. End to end growth of microtubules, consistent microtubule association with the treadmilling were attractive but hardly applicable to interprete the mitosis in vivo. Dynamic instability proposed by Mitchison and Kirschner (1984) and Kirschner and Mitchison (1986), and breathing and annealing hypothesis proposed by Salmon et al. (1984) could be more realistic but some reservations still remain. We feel we need more elaborated data to explain the mechanism of mitosis. So far, we know that chromosomal movement during mitosis is primarily regulated by the labile association of spindle microtubules and that cytokinesis is primarily controlled by polymerized actin.

Antimitotic poisons such as Colchicine or Vinca alkaloids, are useful drugs to study the microtubule association but are not described in this paper (Please see the detailed description on this subject published by Dustin, 1984).

In this article, we shall concentrate on discussing the isotope effect of $\mathrm{D}_{2} \mathrm{O}$ on tubulin polymerization both in vivo and in vitro and attempts to thermodynamically analyze the tubulin polymerization-depolymerization. We also report details of the chemical efficacies and the relationship with their chemical structures of the mitotic arresters, a new family of drugs such as T-1 and its derivatives and analogues, and their biological effects. We found them through our intense and systematic survey for microtubule assembly in the spindles of dividing sea urchin eggs, and we believe them to be powerful molecular probes in deciphering the problems of tubulin polymerization both in vivo and in vitro. Further investigations are in progress in our laboratories on the molecular effects of these drugs on chromosome arrangement in metaphase, alteration of spindle poles and the initiation of anaphase chromosome movement.

\section{Birefringence of the mitotic spindle}

The birefringence (BR) of the mitotic spindle can be yielded by a system of highly oriented molecules, fine structures such as microtubules and microfilaments, or secondary molecules trapped in between fine structures. When a preliminary calculation for the form birefringence using Wiener's equation (66) was attempted based on the number and the volume of fractions containing spindle microtubules, it did not agree with what we measured. This discrepancy was thought to be due to the difficulties in preserving labile microtubules in the spindle.

To overcome these difficulties, several technical modifications were made. Isolated meiotic spindles from mature oocytes of the star fish, Pisaster ochraceus, were used for experimentation (3). The choice of isolated spindles rather than intact spindles was predicted as follows. a) The thorough imbibition of the intratubular space with a defined refractive index was essential for exact analysis of from BR. b) The dimension of the specimen must be readily measureable. c) Light scattering and BR from extraneous sources must be held to a minimum. d) Isolated spindles must be clean and not affected by the optical or chemical influences of surrounding cytoplasm.

The metaphase-arrested meiosis I spindle can be isolated in quantity from the star fish, $P$. ochraceus (Fig. 1D). These isolates are relatively clean and, in the regions between the chromosomes and the poles, show little else other than microtubules (Fig. 2). The BR and dimensions are uniform in these isolates. Moreover, the BR of isolates, which remained close to the value in live spindles, was unchanged upon fixation. The isolates could be immersed in a way by which the same BR returned when the refractive index of the imbibing medium was brought back to the original value. 


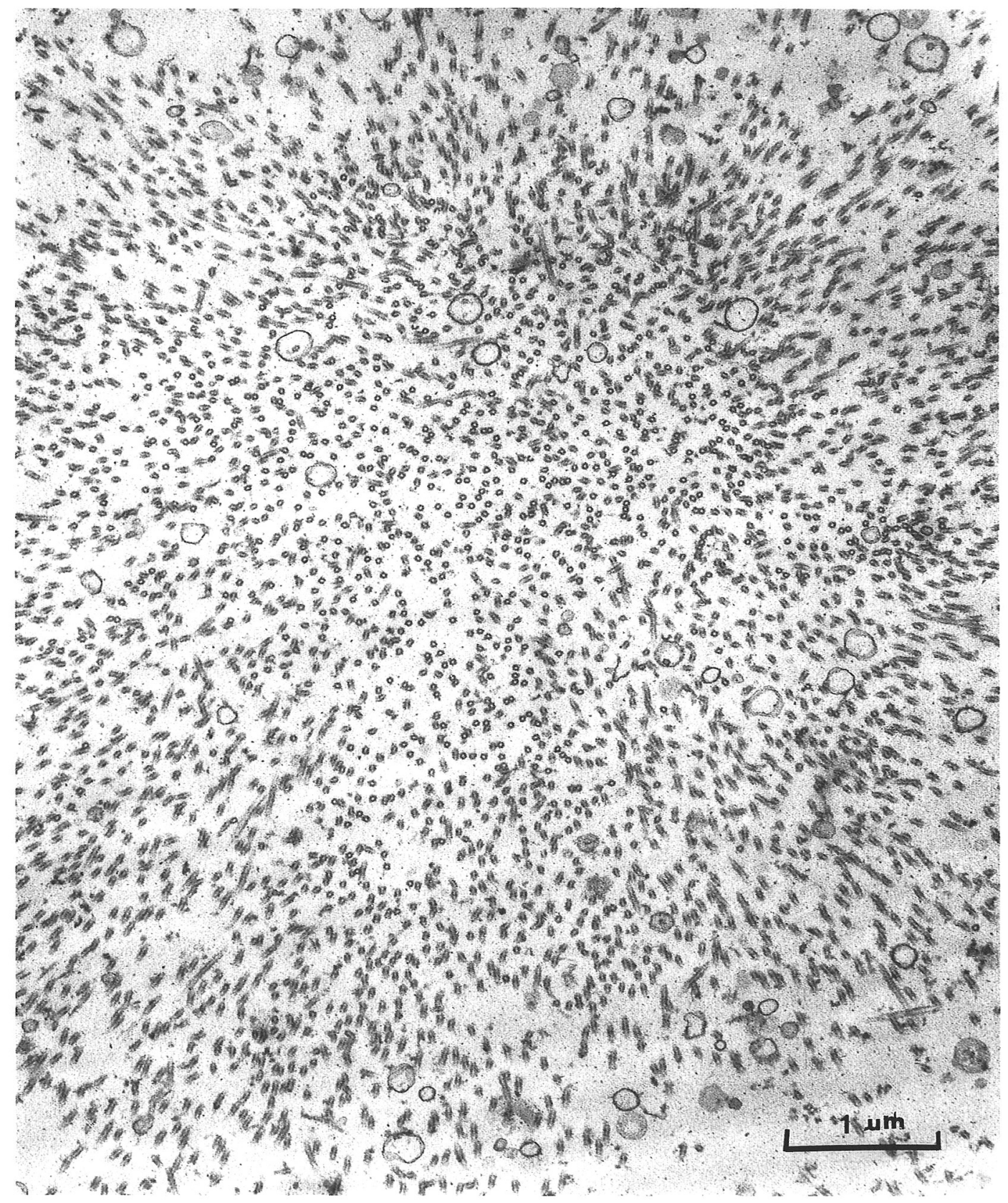

Fig. 2. Cross section of an isolated metaphase spindle of Pisaster ochraceus is mainly occupied by microtubules and little else. These microtubules in the mid-spindle region are mostly aligned parallel to the spindle axis. Some of the vesicles appeared in the photograph are degenerated mitochondria resulting from the isolation and fixation procedure $(47,50)$. 


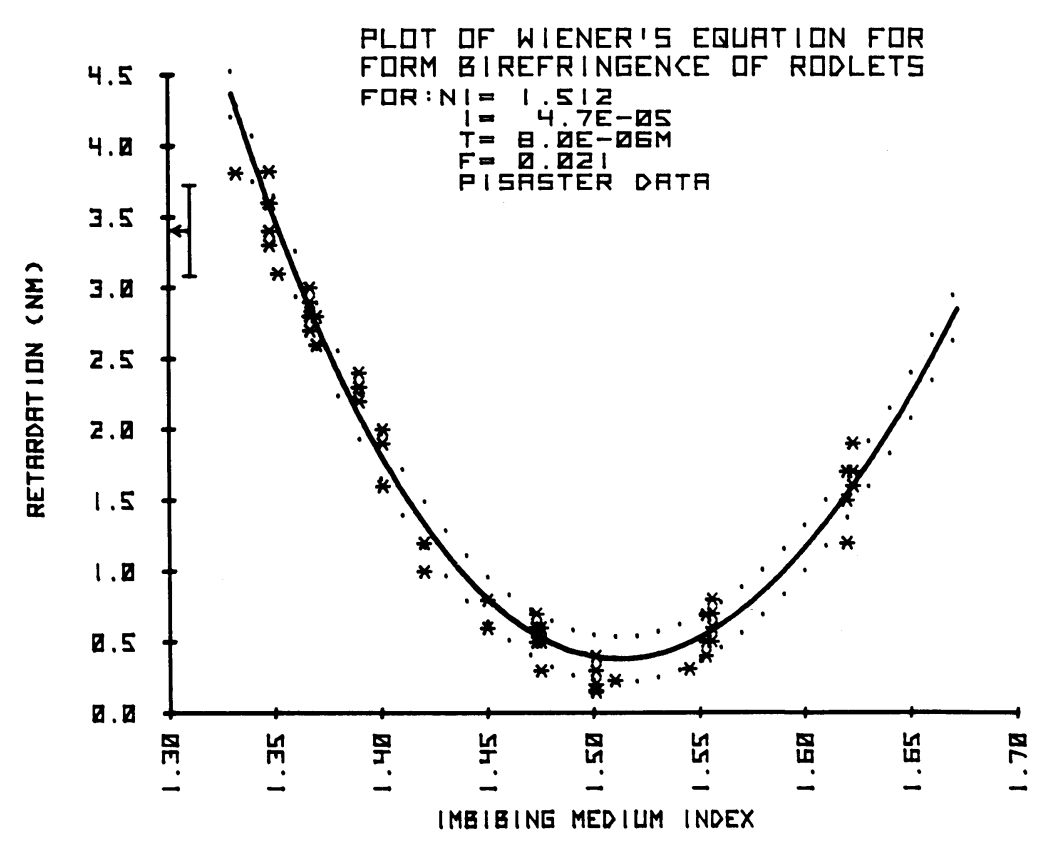

Fig. 3. Computer plot of the best-fit Wiener curve (solid line) with Pisaster imbibition data points to which the curve was fitted. The dotted lines represent the theoretical retardation with standard deviation. The error bar with arrow shown at the ordinate represents the mean and standard deviation of the retardation measured in intact living spindles (49).

The BR of mixed bodies composed of oriented rodlets or platelets whose thickness is well below the wave length of light is believed to arise from two sources. a) An intrinsic BR due to the intramolecular anisotropy of the rodlets or platelets, and b) a form BR due to the anisotropic arrangement of the fine structure. Wiener (1912), and Bragg and Pippard (1953) have derived equations which relate the form BR in terms of dielectric anisotropy to the volume fraction occupied by the rodlets or platelets, their refractive index or dielectric constant, and the refractive index of the second phase in which the rodlets or platelets are immersed.

Isolated spindles in 12\% hexylene glycol, pH 6.3 were mounted between gelatin pericles in the Rose chamber, fixed with $3 \%$ glutaraldehyde, and then perfused with solutions with various refractive indices. Spindle retardations (BR) were measured with a Brace-Köhler compensator using mercury green light as the illuminating source. The volume fraction of the microtubules was calculated from electron micrographs, X-ray diffraction and hydrodynamic data.

Figure 3 shows the best-fit Wiener curve with Pisaster spindle imbibition data. From this execution, we obtained the rodlet refractive index $\left(\mathrm{n}_{1}\right)=1.512$, rodlet volume fraction $(f)=0.0206$, coefficient of intrinsic $B R=4.7 \times 10^{-5}$, and coefficient of BR of spindle $=5 \times 10^{-4}(49)$.

Since the isolated spindles are not, or only minimally, contaminated with other fine structures or protein aggregates, it was concluded that the spindle BR in fact reflects the exact amount of oriented microtubules.

II. Effect of heavy water $\left(\mathrm{D}_{2} \mathrm{O}\right)$ on the mitotic spindles in vivo 
Heavy water $\left(D_{2} O\right)$ enhances spindle volume and BR. For instance, using the metaphase-arrested meiosis I spindle of the oocyte of Pectinaria gouldi, Inoué and Sato (1967) found an 8-fold increase in the spindle volume and practically a doubling in retardation. The increase of volume and retardation depends on the concentration of $\mathrm{D}_{2} \mathrm{O}$ and the stage of mitosis. The maximum increase is obtained by applying $45 \% \mathrm{D}_{2} \mathrm{O}$ during the metaphase to the onset of anaphase. This particular concentration to achieve the maximum effect of $\mathrm{D}_{2} \mathrm{O}$ is common for metaphase spindles in various eukaryotes. The changes are rapid, a new state of equilibrium being reached within $2 \mathrm{~min}$ in Pectinaria oocytes, $90 \mathrm{sec}$ in developing Japanese sea urchin eggs (59), and $5 \mathrm{~min}$ in oocytes of Pisaster ochraceus $(47,48)$. The $\mathrm{D}_{2} \mathrm{O}$ effect is completely reversible and can be repeated many times on the same spindle.

$\mathrm{H}_{2}{ }^{18} \mathrm{O}$ has no effect, whereas $\mathrm{HDO}$ and $\mathrm{HD}^{18} \mathrm{O}$ have half the effect of $\mathrm{D}_{2} \mathrm{O}$. pD also has no significant effect. In many respects, the $\mathrm{D}_{2} \mathrm{O}$ effect is quite similar to elevating the temperature within the physiological range. However, the spindle will over-stabilize or freeze with the application of a high concentration of $\mathrm{D}_{2} \mathrm{O}$.

To compare the effect of temperature and $\mathrm{D}_{2} \mathrm{O}$, attempts were made to analyze the association-dissociation reaction of the spindle by a thermodynamic approach $(12,14,47,50)$. Knowing the physical stability, we chose the metaphase arrested meiosis I spindle of the mature oocyte of Pisaster ochraceus as the experimental material. Thermodynamic parameters were calculated from retardation measurements at various temperatures with or without $\mathrm{D}_{2} \mathrm{O}(47,48)$. In sea water, we obtained $\Delta \mathrm{H}=58.9 \mathrm{kcal} / \mathrm{mol}, \Delta \mathrm{S}=205.9 \mathrm{eu}$, and $\Delta \mathrm{F}=-1.1 \mathrm{kcal} / \mathrm{mol}$. In $45 \%$ $\mathrm{D}_{2} \mathrm{O}$ the values were $\Delta \mathrm{H}=29.55 \mathrm{kcal} / \mathrm{mol}, \Delta \mathrm{S}=106.3 \mathrm{eu}$, and $\Delta \mathrm{F}=-0.9 \mathrm{kcal} / \mathrm{mol}$. These values are similar to those obtained for Chaetopterus spindle (12) and Pectinaria spindle (4). Both association and dissociation processes appear to follow first-order kinetics. Activation energy $\left(E_{a c t}\right)$ for the association reaction is $45 \mathrm{kcal} / \mathrm{mol}$ in sea water and $39 \mathrm{kcal} / \mathrm{mol}$ in sea water containing $\mathrm{D}_{2} \mathrm{O}$. $\mathrm{E}_{\text {act }}$ for the dissociation reaction by removing $\mathrm{D}_{2} \mathrm{O}$ is $15 \mathrm{kcal} / \mathrm{mol}$. These data support the hypothesis that the "spindle reaction" is due to a reversible association of tubulin dimers into linearly aggregated polymers by a first-order reaction. However, the difference between both $\Delta \mathrm{H}$ and $\Delta \mathrm{S}$ in control and $\mathrm{D}_{2} \mathrm{O}$ spindles and their similar $E_{\text {act }}$ suggest that $\mathrm{D}_{2} \mathrm{O}$, in fact, elevates the concentration of polymerizable tubulin dimers.

The coefficient of $B R\left(n_{e}-n_{0}\right)$ of both control and $D_{2} O$ spindle remains constant at $5 \times 10^{-4}$. This means there is a significant increase in microtubules in $\mathrm{D}_{2} \mathrm{O}$ spindle with no disturbance of the original population density. From the electron micrographs, we found the total number of spindle microtubules increased from 4,200 in the control to 10,000 in $\mathrm{D}_{2} \mathrm{O}$ spindle at $13^{\circ} \mathrm{C}$, having an average population density of 106 per $\mu \mathrm{m}^{2}$. The length of each spindle microtubule also was increased by $\mathrm{D}_{2} \mathrm{O}$. The estimated rate of tubulin association was calculated to be $1 \times 10^{2}$ monomers/sec per microtubule in Pisaster oocyte (48). The comparison between $\mathrm{D}_{2} \mathrm{O}$ and control spindles is summarized in Table 1.

The $\mathrm{D}_{2} \mathrm{O}$ effect on the mitotic spindle was thought to occur only in specialized cells such as mature oocytes or unfertilized eggs which contain a large amount of polymerizable tubulin. Arguments were based presumably on the lack of sufficient tubulin source in somatic cells which were supposed to synthesize enough polymerizable tubulin during a cell cycle to support spindle assembly. However, this assumption could be wrong because we found the $\mathrm{D}_{2} \mathrm{O}$ effect can be clearly demonstrated in some tissue culture cells. For example, the $\mathrm{D}_{2} \mathrm{O}$ effect on the spindle 
TABLE 1. COMPARISON OF $\mathrm{D}_{2} \mathrm{O}$-SPINDLE VERSUS CONTROL SPINDLE. MATERIAL: Pisaster OCHRACEUS (50)

\begin{tabular}{lcc}
\hline \multicolumn{1}{c}{ Condition of isolation } & $13^{\circ} \mathrm{C}, 12 \% \mathrm{HG}$ & $45 \% \mathrm{D}_{2} \mathrm{O}, 13^{\circ} \mathrm{C}, 12 \% \mathrm{HG}$ \\
\hline Pol. $M$. & 3.8 & 5.4 \\
Retardation (BR), nm & 8.0 & 12.4 \\
Spindle diameter, um & $5 \times 10^{-4}$ & $5 \times 10^{-4}$ \\
Coefficient of BR $\left(n_{\mathrm{e}}-n_{0}\right)$ & & \\
$E . M$. & $24 \mathrm{~nm}, 15 \mathrm{~nm}$ & $24 \mathrm{~nm}, 15 \mathrm{~nm}$ \\
Dimension of microtubule OD and ID & 106 & 106 \\
Density of microtubules $/ \mu \mathrm{m}^{2}$ & 130 & 130 \\
Average number of microtubules in spindle core $/ \mu \mathrm{m}^{2}$ & 4,200 & 10,000 \\
Total number of microtubules per spindle & $5 \times 10^{-4}$ & $5 \times 10^{-4}$ \\
Coefficient of BR $\left(n_{\mathrm{e}}-n_{0}\right)$ & & \\
\end{tabular}

was noted in dividing rat-kangaroo $\mathrm{Pt}-\mathrm{K}_{2}$ cells in monolayer culture condition (50). Knowing that the artificially induced tubulin paracrystals produced with vinblastine can represent almost all the available tubulin in a cell (Fig. 3; 58, 61), we calculated tubulin concentration by summarizing total amount of paracrystals recorded on polarization micrographs. We estimate that at most $18 \%$ of tubulin is used for spindle assembly in a dividing $\mathrm{Pt}-\mathrm{K}_{2}$ cell. The same value is also obtained for dividing tissue-cultured salamander lung epithelial cells. The order of magnitude of tubulin consumption for spindle assembly in these cells is comparable to that for developing zygotes such as the fertilized sea urchin eggs, in which about $5-8 \%$ of the cytoplasmic tubulin is presumably used to assemble the spindle in each mitosis.

Now a question arises: Can $\mathrm{D}_{2} \mathrm{O}$ affect anaphase chromosome movement? $\mathrm{D}_{2} \mathrm{O}$ increases the number of spindle microtubules as well as their length. If $\mathrm{D}_{2} \mathrm{O}$ is acting in favor of tubulin association, then it may be unfavorable for tubulin dissociation. Thus, $\mathrm{D}_{2} \mathrm{O}$ may retard the anaphase chromosome movement in dividing cells. To ex-

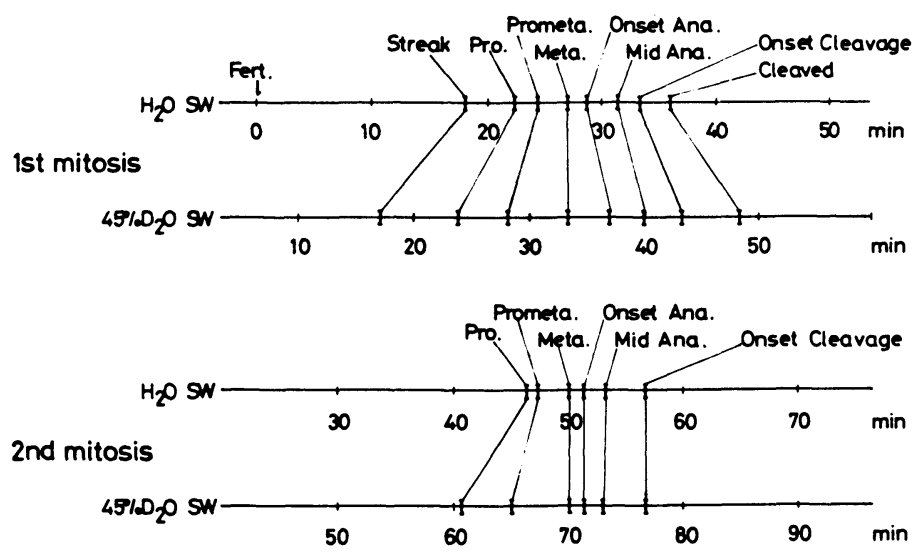

Fig. 4. Time course of mitosis in developing eggs of Japanese summer sea urchin, Mespilia globulus, immersed in $\mathrm{H}_{2} \mathrm{O}$ or $\mathrm{D}_{2} \mathrm{O}(60)$. 
amine this possibility, we used developing sea urchin eggs of Mespilia globulus and Hemicentrotus pulcherrimus because of their synchronous mitotic events and rather exact time schedule for development (60). As shown in Fig. 4, we found that the mitotic processes of developing sea urchin eggs (M. globubus) in the first and the second division were greatly extended by immersing them in $\mathrm{D}_{2} \mathrm{O}$ sea water. However, the retardation of the mitotic process mainly occurred in prophase to metaphase, and no anaphase chromosome movement was disturbed by $\mathrm{D}_{2} \mathrm{O}$. In fact, neither acceleration nor retardation of the speed of anaphase chromosome movement was detected. We also confirmed that $H$. pulcherrimus responded in the same manner with $\mathrm{D}_{2} \mathrm{O}(60)$. These observations imply that $\mathrm{D}_{2} \mathrm{O}$ elevates polymerizable tubulin concentration but has little effect on tubulin dissociation in vivo.

\section{Size of the polymerizable tubulin pool in sea urchin eggs}

From the thermodynamic analysis of the $\mathrm{D}_{2} \mathrm{O}$ effect on spindle assembly in vivo, we postulated that $\mathrm{D}_{2} \mathrm{O}$ could increase the concentration of polymerizable tubulin in the sea urchin eggs. However, we did not have evidence showing that $\mathrm{D}_{2} \mathrm{O}$ converts the unpolymerizable tubulin into a polymerizable form. Tubulin can form paracrystals in living eukaryotic cells when the cells are incubated with Vinca alkaloids such as vinblastine or vincrystine. The yield of tubulin paracrystals, "VBcrystals," was greatly enhanced by simultaneous incubation with $10^{-4} \mathrm{M}$ vinblastine and $10^{-4} \mathrm{M}$ Colcemid in unfertilized sea urchin eggs (Fig. 5), but the yield was always reduced when eggs were fertilized (61). We thought that changes of intracellular compartmentalization of the cytoskeleton occurred during fertilization, causing a reduction in polymerizable tubulin molecules. If we can demonstrate that $\mathrm{D}_{2} \mathrm{O}$ releases the suppressed tubulin molecules in fertilized eggs and allows these eggs to form the same amount of tubulin paracrystals as the unfertilized eggs, this could be a direct proof of the isotope effect of $\mathrm{D}_{2} \mathrm{O}$.

For this purpose, we used mature eggs of Pseudocentrotus depressus and incubated them in artificial sea water containing $10^{-4} \mathrm{M}$ vinblastine sulfate and $10^{-4}$ $\mathrm{M}$ Colcemid at $20^{\circ} \mathrm{C}$ for $5 \mathrm{~h}$ with or without $\mathrm{D}_{2} \mathrm{O}$.

After the incubation, eggs were examined under a polarizing microscope to observe the birefringent tubulin paracrystals. The volume estimation of each crystal within an egg was obtained by cubing the geometric mean of each dimension. The total crystal volume per cell is the sum of the estimated volume of each crystal found within a cell. For the biochemical assay, crystals were isolated, purified and the tubulin concentration per egg was determined (61). We found that the yield of VB-crystal in mature unfertilized eggs was fairly constant regardless of the presence or absence of $\mathrm{D}_{2} \mathrm{O}$. On fertilization, the yield of crystals decreased markedly as compared with that of unfertilized eggs. However, when an adequate concentration of $\mathrm{D}_{2} \mathrm{O}$ was present during incubation, the yield was restored to the level seen with unfertilized eggs.

These results are evidence that tubulin molecules in unfertilized sea urchin eggs are in the polymerizable state but become masked and partly unpolymerizable after fertilization, and that $\mathrm{D}_{2} \mathrm{O}$ releases from the masked state and converts unpolymerizable tubulin molecules into an active polymerizable state. Summarized data are shown in Fig. 6 (61).

IV. Effects of $\mathrm{D}_{2} \mathrm{O}$ on tubulin polymerization in vitro

Although effects of $\mathrm{D}_{2} \mathrm{O}$ on the polymerization of other biological polymers such 

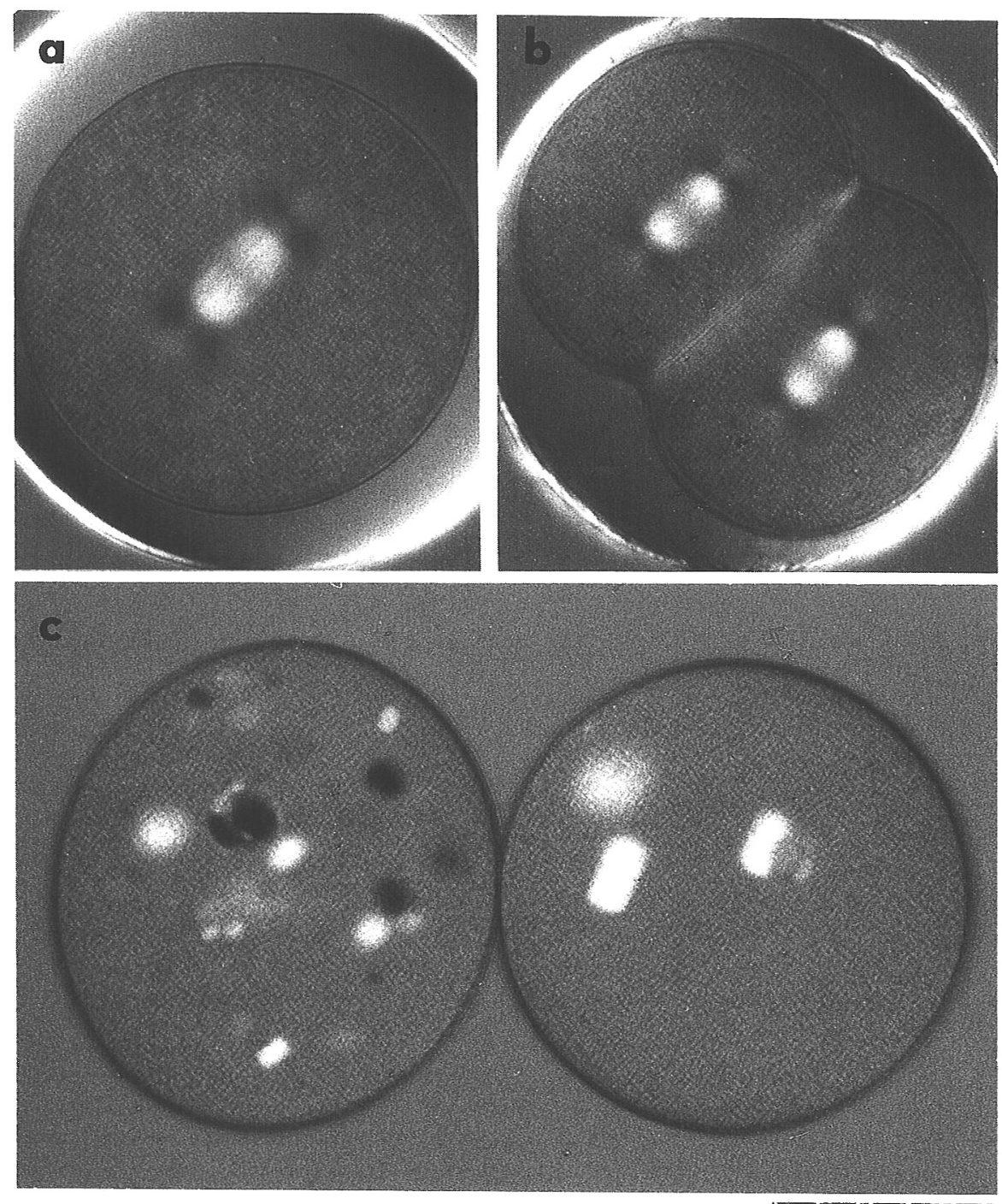

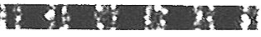

Fig. 5. First and second spindles in metaphase observed in developing embryo of sea urchin Clypeaster japonicus, vs. tubulin paracrystal induced in gamates of same species by simultaneous incubation with $10^{-4} \mathrm{M}$ vinblastine and Colcemid. It is the proof of the existence of a large amount of polymerizable tubulin dimer in the sea urchin cytoplasm. Scale; $1 \mathrm{div} .=10 \mu \mathrm{m}$.

as tobacco mosaic virus or flagellin were thoroughly investigated $(19,63)$, only limited data are available on the $\mathrm{D}_{2} \mathrm{O}$ effect on the polymerization of tubulin in vitro. Olmsted and Borisy (1973) reported that the rate of polymerization was promoted by $\mathrm{D}_{2} \mathrm{O}$ at a concentration of less than $30 \%$ but that the final extent of polymer formation tended to decrease in $50 \% \mathrm{D}_{2} \mathrm{O}$. Because they did not attempt to regulate the $\mathrm{pD}$ of the buffered solution, some reservations remained about their results. Houston et al. (1974) followed up by examining the effects of $\mathrm{D}_{2} \mathrm{O}$ under 


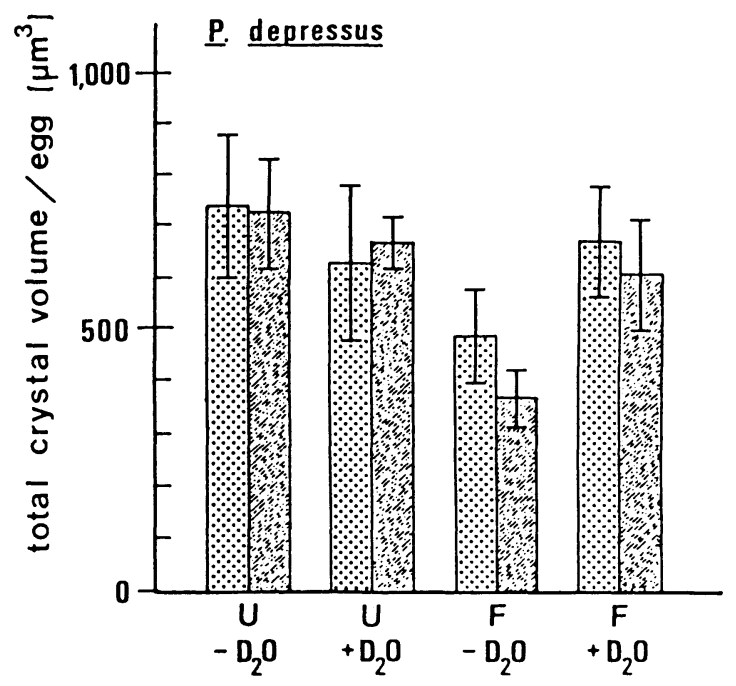

Fig. 6. Histogram showing the total volume of VB-crystals in sea urchin eggs, Pseudocentrotus depressus after $5 \mathrm{~h}$ of incubation at $20^{\circ} \mathrm{C}$. $\mathrm{U}$ and $\mathrm{F}$ represent unfertilized and fertilized eggs. Each column records the mean of 5 eggs; the bar shows the standard deviation. Each screen tone represents a separate batch of eggs. Only the fertilized/nondeuterated group significantly decreased in volume. The concentration of $\mathrm{D}_{2} \mathrm{O}$ was $40 \%$ (59).

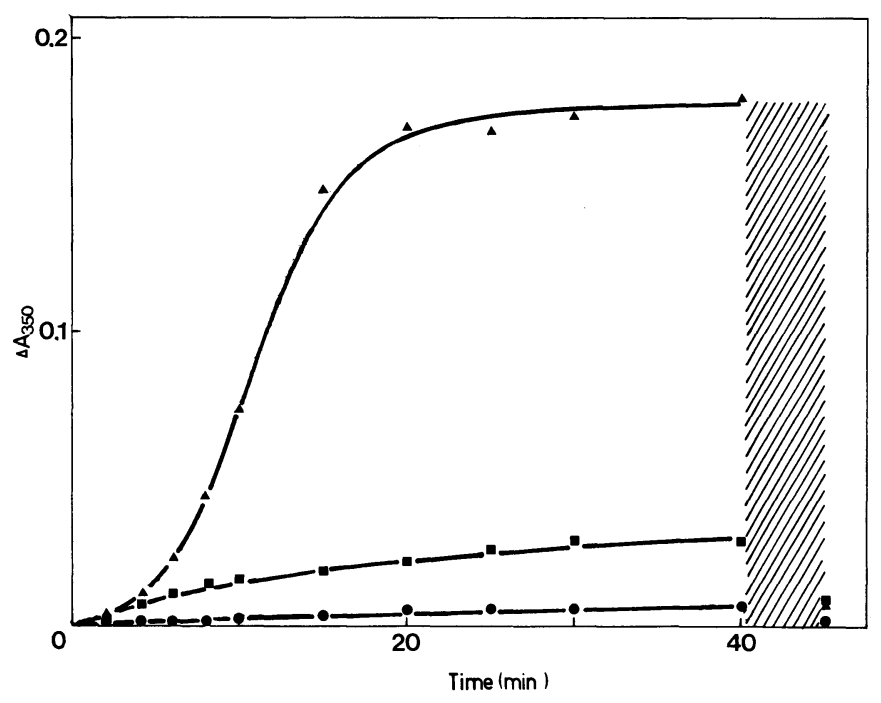

Fig. 7. Time course of the polymerization of bovine brain tubulin in the presence of $\mathrm{D}_{2} \mathrm{O}$. Polymerization reaction was initiated by warming the tubulin solution $(2.0 \mathrm{mg} / \mathrm{ml})$ in reassembly buffer which consisted of $0.1 \mathrm{M}$ PIPES (pD 6.9), $1 \mathrm{mM}$ EGTA, $0.5 \mathrm{mM} \mathrm{MgSO}_{4}$ and $1 \mathrm{mM} \mathrm{GTP}^{\circ} 37^{\circ} \mathrm{C}$ in the absence of $\mathrm{D}_{2} \mathrm{O}(\bullet)$, and in the presence of $40 \% \mathrm{D}_{2} \mathrm{O}(\nabla)$ or $80 \% \mathrm{D}_{2} \mathrm{O}(\Delta)$. Dashed area indicates immersion time in an ice-water bath (15). 
conditions where the $\mathrm{pD}$ was regulated, using a tubulin fraction isolated from bovine brain, and found that the rate of polymerization was suppressed by $\mathrm{D}_{2} \mathrm{O}$. Their tubulin fraction, however, contained microtubule associated proteins (MAPs), which are known to be stimulating factors for tubulin polymerization. Therefore, a question was raised. Were the effects of $\mathrm{D}_{2} \mathrm{O}$ obtained by Houston et al. partially mediated by MAPs? To answer this question, we used a pure tubulin fraction, which does not contain MAPs, to examine effects of $\mathrm{D}_{2} \mathrm{O}$ in vitro.

Tubulin was purified from bovine brains by phosphocellulose column chromatography according to the method of Weingarten et al. (65). The polymerization reaction was monitored using turbidimetry in a solution whose $\mathrm{pD}$ value was kept constant at 6.9 (15). Pure brain tubulin, which is free of MAPs, is difficult to polymerize unless a polymerization system contains an organic solvent such as DMSO or glycerol $(34,44)$. However, $\mathrm{D}_{2} \mathrm{O}$ could initiate spontaneous polymerization of brain tubulin even at low protein concentrations. In the presence of $\mathrm{D}_{2} \mathrm{O}$, polymerization induced by warming was enhanced as the $\mathrm{D}_{2} \mathrm{O}$ concentration increased, up to $80 \%$ (Fig. 7). Within this concentration range, both the rate and the final extent of polymerization were increased. Polymers in $\mathrm{D}_{2} \mathrm{O}$ were observed under an electron microscope, and we found that only microtubules were assembled in the presence of $\mathrm{D}_{2} \mathrm{O}$ and neither amorphous aggregates nor sheets were formed. Because these microtubules were depolymerized by chilling, we considered the polymerization reaction in $\mathrm{D}_{2} \mathrm{O}$ to be reversible. Subsequent electron microscopic observations confirmed that no microtubule remained in the cooled tubulin solution. The enhancement of both the initial rate and the final extent of polymerization by $\mathrm{D}_{2} \mathrm{O}$ could be due to the increase in the number of nuclei as well as in the length of polymers.

The critical concentration for tubulin polymerization decreased with the increase in $\mathrm{D}_{2} \mathrm{O}$ concentration, suggesting that the promotion of tubulin polymerization in the presence of $\mathrm{D}_{2} \mathrm{O}$ was due to the reduction of the critical concentration. Using the temperature dependence of the critical concentrations as summerized in Table 2, we attempted a thermodynamic analysis of the effects of $\mathrm{D}_{2} \mathrm{O}$ on tubulin polymerization. The resulting linear van't Hoff plots are shown in Fig. 8. The slope of van't Hoff plots of the propagation equilibrium in the presence of MAPs was steep below $20^{\circ} \mathrm{C}$, whereas the slope above $20^{\circ} \mathrm{C}$ became gentle (18). The apparent biphasic property of van't Hoff plots might be due to the presence of MAPs. Thus, the linearity of our plots, which are similar to the results obtained either from the tubulin polymerization in DMSO (44) or sperm outer doublet tubulin polymerization (40), can be attributed to the absence of MAPs in our tubulin preparation.

We caluculated the standard enthalpy change $(\Delta \mathrm{H})$ and the standard entropy

TABLE 2. TEMPERATURE DEPENDENCE OF THE CRITICAL CONCENTRATION (CC) FOR THE TUBULIN POLYMERIZATION, AT VARIOUS CONCENTRATIONS OF $\mathrm{D}_{2} \mathrm{O}$ (15).

\begin{tabular}{llllll}
\hline \multirow{2}{*}{ Temperature } & \multicolumn{2}{c}{$(\mathrm{mg} / \mathrm{ml})$} & & & \\
\cline { 2 - 5 } & $\mathrm{D}_{2}$ concn.: & $20 \%$ & $50 \%$ & $60 \%$ & $80 \%$ \\
\hline $20^{\circ} \mathrm{C}$ & & 5.25 & 3.13 & 1.80 & 0.95 \\
$25^{\circ} \mathrm{C}$ & & 4.40 & 2.58 & 1.33 & 0.63 \\
$30^{\circ} \mathrm{C}$ & & 3.63 & 2.10 & 0.99 & 0.35 \\
$37^{\circ} \mathrm{C}$ & & 2.97 & 1.67 & 0.65 & 0.15 \\
\hline
\end{tabular}




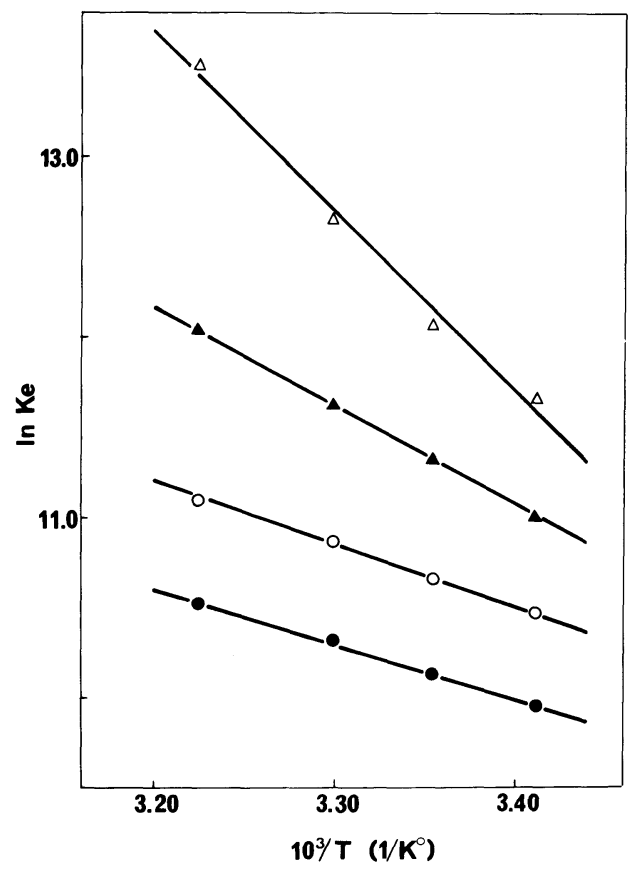

Fig. 8. Van't Hoff plots of the polymerization of brain tubulin in the presence of $\mathrm{D}_{2} \mathrm{O} \cdot \mathrm{D}_{2} \mathrm{O}$ concentration is $20 \%(\bullet), 50 \%(\bigcirc), 60 \%(\triangle)$ and $80 \%(\triangle)$. Resulting thermodynamic parameters are summarized in Table 3 (15).

change $(\Delta S)$ from the slopes of the straight lines of our van't Hoff plots and from the intercepts of the lines with the ordinate, respectively. As summerized in Table 3, all the $\Delta \mathrm{H}$ and $\Delta \mathrm{S}$ values were positive and they increased in association with the elevation of the $D_{2} \mathrm{O}$ concentration. Because of the positive enthalpy change $(\Delta \mathrm{H})$ of the polymerization, the driving force of polymerization reaction should come from the entropy $(\Delta S)$ increase. Entropy-driven processes in biological systems are primarily hydrophobic interactions (33). Kresheck et al. (1965) have predicted that hydrophobic interactions between protiated amino acid side chain will be stronger in $\mathrm{D}_{2} \mathrm{O}$ than in $\mathrm{H}_{2} \mathrm{O}$. Thus, we suggested that the strengthening of intra- and/or inter-molecular hydrophobic interactions of tubulin molecules might contribute to the $\mathrm{D}_{2} \mathrm{O}$ dependent enhancement of the polymerization.

These data support the presumption that the results obtained in in vivo ex-

TABLE 3. COMPARISON OF THERMODYNAMIC PARAMETERS OF THE TUBULIN POLYMERIZATION AT VARIOUS CONCENTRATIONS OF $\mathrm{D}_{2} \mathrm{O}(15)$.

\begin{tabular}{ccc}
\hline $\mathrm{D}_{2} \mathrm{O}$ concn. & $\triangle \mathrm{H}(\mathrm{kcal} / \mathrm{mol})$ & $\triangle \mathrm{S}$ (entropy unit) \\
\hline $20 \%$ & 6.10 & 40.5 \\
$50 \%$ & 6.77 & 43.9 \\
$60 \%$ & 10.8 & 58.8 \\
$80 \%$ & 19.8 & 90.5 \\
\hline
\end{tabular}


periments could be due to the direct involvement of $\mathrm{D}_{2} \mathrm{O}$ in tubulin polymerization. Some discrepancies, however, still existed between the results of in vivo and in vitro experiments. For instance, the optimum concentration of $\mathrm{D}_{2} \mathrm{O}$ for microtubule assembly in living cells was $45 \%$ (13), whereas tubulin polymerization in vitro was progressively enhanced with the increase in $\mathrm{D}_{2} \mathrm{O}$ concentration, and no limiting point was detected up to $80 \%$. Furthermore, results obtained from in vivo examinations did not support the idea that $\mathrm{D}_{2} \mathrm{O}$ enhanced hydrophobic interactions of the tubulin molecules in living, dividing cells $(47,50,60)$. We could eliminate the possibility that the difference between these two systems was not due to the source of tubulin, because any remarkable difference in the $\mathrm{D}_{2} \mathrm{O}$ dependant enhancement of polymerization could not be detected between the brain and the sea urchin egg tubulin (15). Rather, the difference might be ascribed to the regulatory factor(s) such as calmodulin, microtubule associating proteins, capping GTP or co-factors, which directly or indirectly participated in microtubule assembly in the living cell, were missing from the in vitro system.

\section{The screening for new mitotic arresters from microbial metabolites}

i). Screening for mitotic arresters. A few years ago we began a systematic survey of new anti-neoplastic drugs which can react with cytoskeletal components and arrest living, dividing cells. The criteria we applied during the survey were: 1 ) the chemicals must react with spindle microtubules either directly or indirectly and stabilize microtubules in situ; 2) they must prevent microtubular dissociation without altering the microtubule configuration; 3 ) the effective concentration of drugs must be low and should be free from any side effects; 4) the effect of the drug treatment should be reversible when the drug is washed out in vivo; and 5) there must be a molecular basis for the interpretation of the action of a given drug.

Mitotic events in eukaryote are tightly linked to the cell cycle. Time requirement for the spindle assembly and disassembly, overall spindle shape and the birefringence in the process of mitosis are sure indications to judge whether or not all spindle components have been assembled in an order and performed their physiological roles following the built-in program. Changes in the volume, the shape and the birefringence of spindles can be considered to be the reflection of the inhibitory effects of the applied drugs. We found that spindles assembled in fertilized sea urchin eggs are excellent materials for this purpose. They possess a great advantage to examine the effects of drugs because of the ample supply of materials, easy handling, fast and synchronous development and the established stabilization technique. Moreover, spindles formed in fetilized eggs of Temnopleurus hardwicki, or Clypeaster japonicus can be visualized in vivo with a sensitive polarization microscope without stabilization. Thus, we used sea urchin eggs intensely as an unique in vivo probe to examine the chemical efficacy of mitotic arresters $(22,23$, 27, 30, 51, 53).

Fertilized Japanese sea urchin eggs of, Hemicentrotus pulcherrimus, Pseudocentrotus depressus, Anthocidaris crassispina, Clypeaster japonicus and Temnopleurus hardwicki were intensely used for the present survey, and the process of spindle for-" mation, spindles arrested in metaphase or the stabilized mitotic apparatuses in drug-treated eggs were followed with a polarization microscope with rectified optics or a Nomarski differential interference microscope (Nikon, Tokyo).

The culture broth often contains various metabolites. The side effects, brought about by the coexisting metabolites in the broth, often confuse the evaluation of the 
desirable activity, even if the broth contains a desirable compound. The timing to apply the drugs with the broth is critical, so we used Aphidicolin [1], Taxol [2], Maytansine [3] as model compounds to determine the time of application and biological effects on spindle assembly (Fig. 9).

ii). Biological effects of Aphidicolin, Maytansine and Taxol. Aphidicolin, which is known to inhibit DNA synthesis by suppressing the activity of DNA polymerase- $a(11,20,39)$, arrests developing sea urchin eggs in early prometaphase with an intact nuclear membrane when the drug is applied 20 min after fertilization at the concentration of $2 \times 10^{-5} \mathrm{M}$. However, normal spindles with strong birefringence were formed when the drug was introduced after the "streak stage". The metaphase spindles persisted in treated eggs almost one cell cycle, and the chromosomes eventually turned into karyomeres without any sign of an anaphase transition.

Maytansine, on the other hand, shows a rather mild retarding effect on sea urchin

1 Aphidicolin

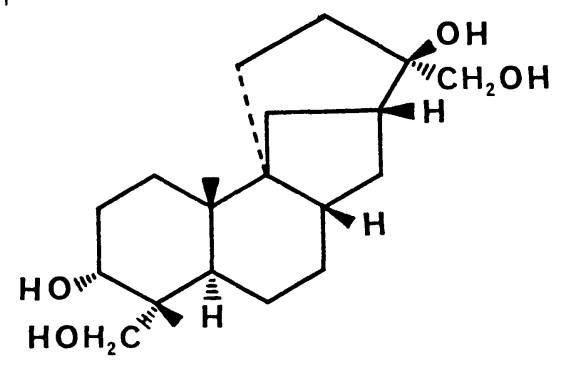

2 Taxol

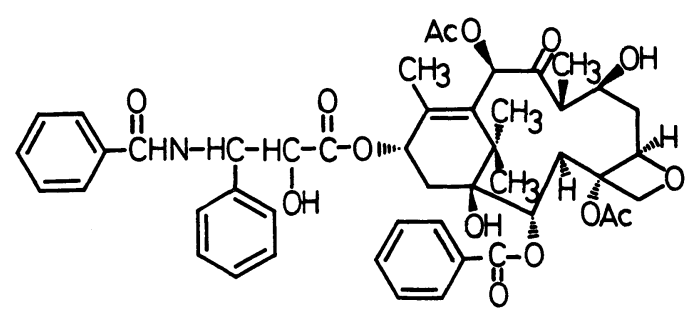

3 Maytansine

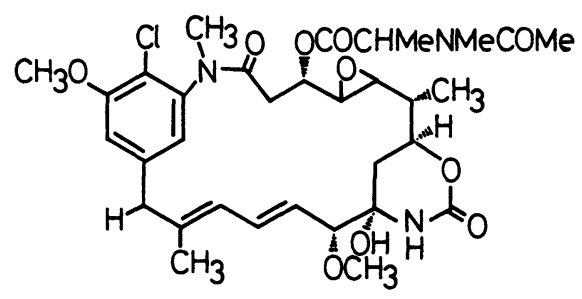

Fig. 9. Representative mitotic arresters and their chemical structures. 
spindles $(43,53)$. Effective concentration is low. When sea urchin eggs are treated with $10^{-7} \mathrm{M}$ of Maytansine immediately after fertilization, the spindle forms on time and anaphase is also initiated but metaphase is prolonged about $20 \mathrm{~min}$ in developing eggs of $P$. depressus. When the drug is applied at the "streak stage", miniature spindles are formed and more or less sustained in metaphase. If the drug is introduced in metaphase, the shape and birefringence of spindles appears to be normal and anaphase proceeds with the same timing as the control.

Taxol has a strong acceleratory effect on in vivo tubulin polymerization and inhibits $\mathrm{Ca}^{2+}$ dependent tubulin depolymerization. In vivo, this drug is also known to stabilize the cytoskeletal microtubules and block cell division at concentrations of $10^{-5}$ to $10^{-6} \mathrm{M}$. When Taxol is applied to winter sea urchin eggs $35 \mathrm{~min}$ after fertilization (approximately in the "streak stage"), metaphase of dividing eggs is greatly extended. $80 \%$ of them were arrested in either full metaphase or early anaphase even 90 min after fertilization.

Taxol lowers the critical concentration of tubulin polymerization, enhances the initial rate of polymerization and raises the final level of tubulin polymers $(25,56,64)$. Comparable effects are also observed in the living, dividing sea urchin eggs. In the eggs of $P$. depressus, spindle shape remained rather constant but the spindle birefringence increased to 1.3 above control levels, suggesting that there are more oriented microtubules in the unit volume of spindle. Few cells managed to divide, and anaphase chromosome movement was almost never observed.

From these observations, we chose $H$. pulcherrimus as a test specimen, and selected following periods for the time to apply the drugs in the forms either the
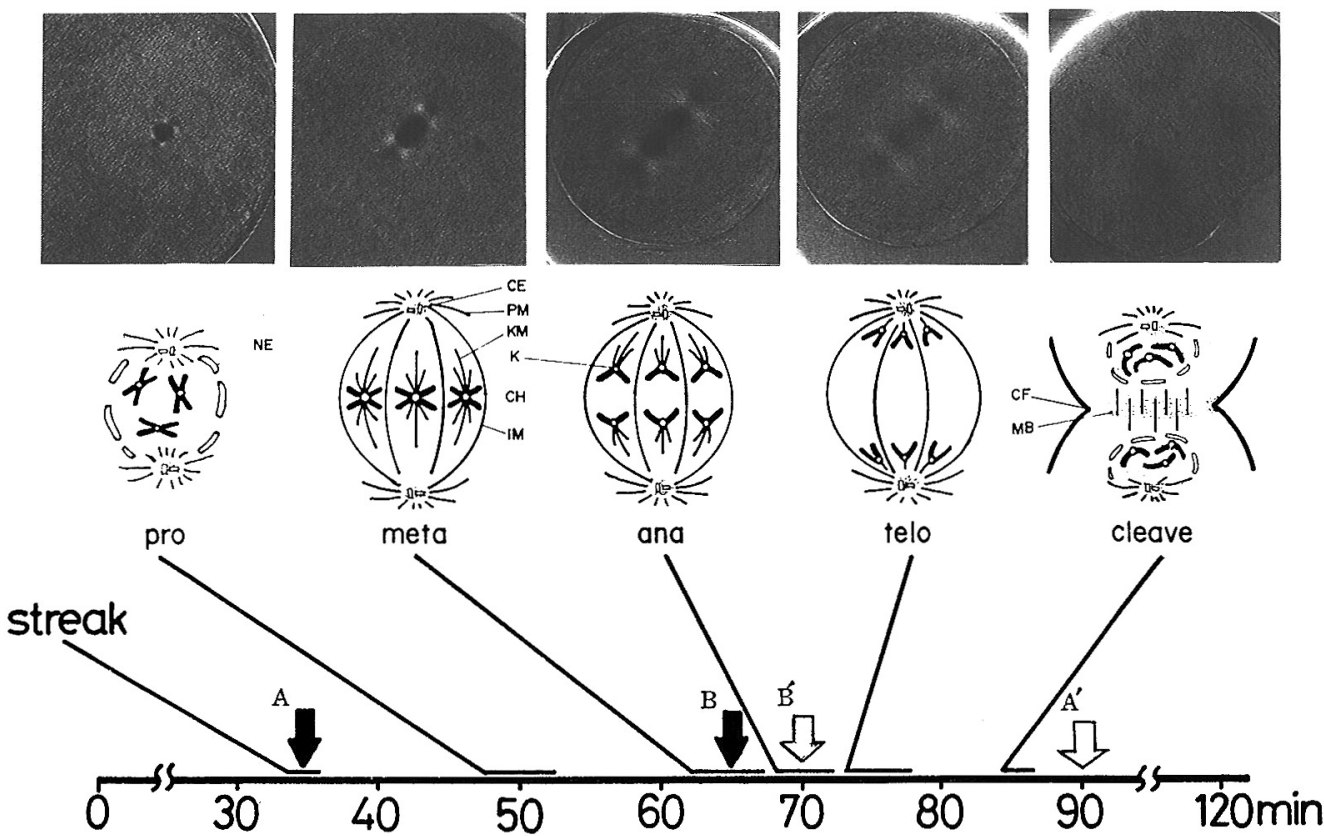

Fig. 10. Time course of the spindle assembly in a fertilized egg of Hemicentrotus pulcherrimus maintained at $19^{\circ} \mathrm{C}$. Black arrows correspond to the time for drug introduction. White arrows indicate the observation points. 
crude broth or the purified isolates. a) Fusion of pronuclei of "streak stage", for instance, $35 \mathrm{~min}$ after the fertilization. b) Prometaphase, $60 \mathrm{~min}$ after the fertilization in same material. c) Pulse treatment between 65 to 70 min after the fertilization in same material and eggs are in metaphase. d) Early anaphase, $70 \mathrm{~min}$ after the fertilization $(25,28)$ (Fig. 10).

iii). T-1,T-2 and T-3 as the mitotic arresters. In 1980, Kobayashi and his colleagues found that culture broth of a soil bacterium, Pseudomonas sp. 218 , possessed a pronounced inhibitory effect on sea urchin embryo development (22). Then, we confirmed that the barrel-shaped spindles were induced by the 400 times diluted solution of the original crude broth when the eggs of $H$. pulcherrimus were treated at streak stage. Spindle morphology was clearly different from the control or the spindles pretreated with known mitotic poisons such as the Colcemid or Vinca alkaloids. Repeated column chromatography of this culture broth yielded three active constituents, and we named them $T-1,2,3$. On the basis of the spectroscopic analysis as well as the synthetic work, T-1, T-2 and T-3 were identified to be 2-n-hex-

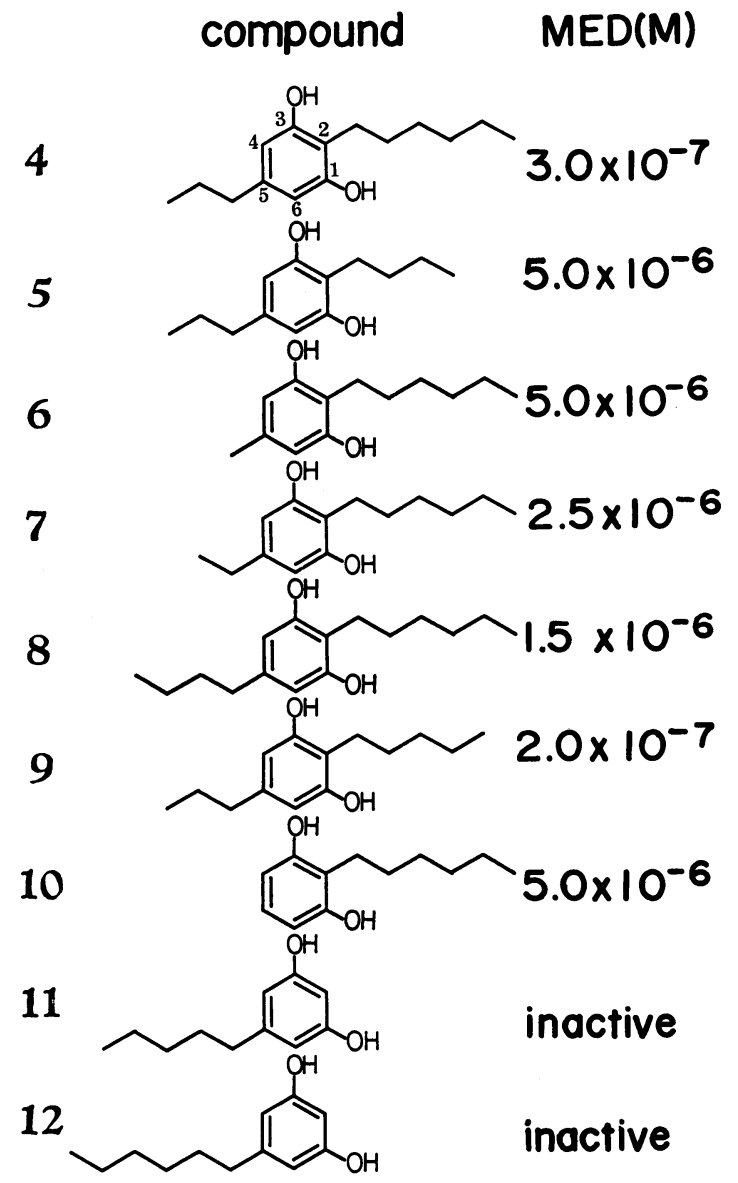

Fig. 11. Potency in barrel-shaped spindle induction of T-series and the derivatives. MED(M): Minimun effective dose. 
yl-5-n-propyl-1,3-benzenediol [4]; 2- $n$-butyl-5- $n$-propyl-1,3-benzenediol [5]; 2- $n$ hexyl-5-methyl-1,3-benzenediol [6], respectively $(24,53)$.

iv). Structure-activity relationship of T-compounds and derivatives. 1,3Benzendiol system (resorcinol) with alkyl side chains at C-2 and C-5 positions is the structural characteristic of these compounds. Chemical modification and derivatization of the $T$ series compounds were made to discern what part of the structural entities is required to exert this unique biological activity. The structural difference between $\mathrm{T}-1$ and $\mathrm{T}-3$ is only one ethylene unit $\left(-\mathrm{CH}_{2}-\mathrm{CH}_{2}-\right)$ at $\mathrm{C}-5$. However, $\mathrm{T}-1$ showed ten times more effect than $\mathrm{T}-3$. This means that a comparatively small change in the side chain can produce fairly dramatic differences in activity in the $T-1$ analogues. Therefore, 2- $n$-hexyl-5-ethyl-1,3-benzenediol [7], having a shorter chain at $\mathrm{C}-5$ by one methylene unit than T-1, and 2- $n$-hexyl-5- $n$-butyl-1,3-benzenediol [8], having a longer chain by one methylene unit, were synthesized. Among these two compounds, $\mathrm{T}-1$ demonstrates as most effective. This indicates that the $\mathrm{C}_{3}$ unit $\left(\mathrm{C}_{3} \mathrm{H}_{7}\right)$ is the optimum length as the side chain at C-5. The length of the carbon chain at C-2 was also optimized by examining newly synthesized compounds [7, 8], T-1, and T-2. All of them possessed the same substitution ( $n$-propyl) at C-5. Thus, it is concluded that $n$-propyl $\left(\mathrm{C}_{5} \mathrm{H}_{11}\right)$ group is the optimum length (Fig. 11).

Among all $\mathrm{T}$ series and their derivatives tested, the compound 9,1,3-benzenediol with an $n$-pentyl at C-2 and an $n$-propyl at C-5, was the most effective and inhibited the first cleavage of fertilized sea urchin eggs at a concentration of $2.0 \times 10^{-7} \mathrm{M}$. This compound was about five times more active than the Colcemid and almost as active as Maytansine. The lipophilicity of the $T$ series is much higher than that of Colcemid or Maytansine. Therefore, the balance between hydrophobicity and hydrophilicity in the molecule was one of the important factors, especially among 2,5-dialkyl-1,3-benzenediols. We concluded that the compound 9 must be the

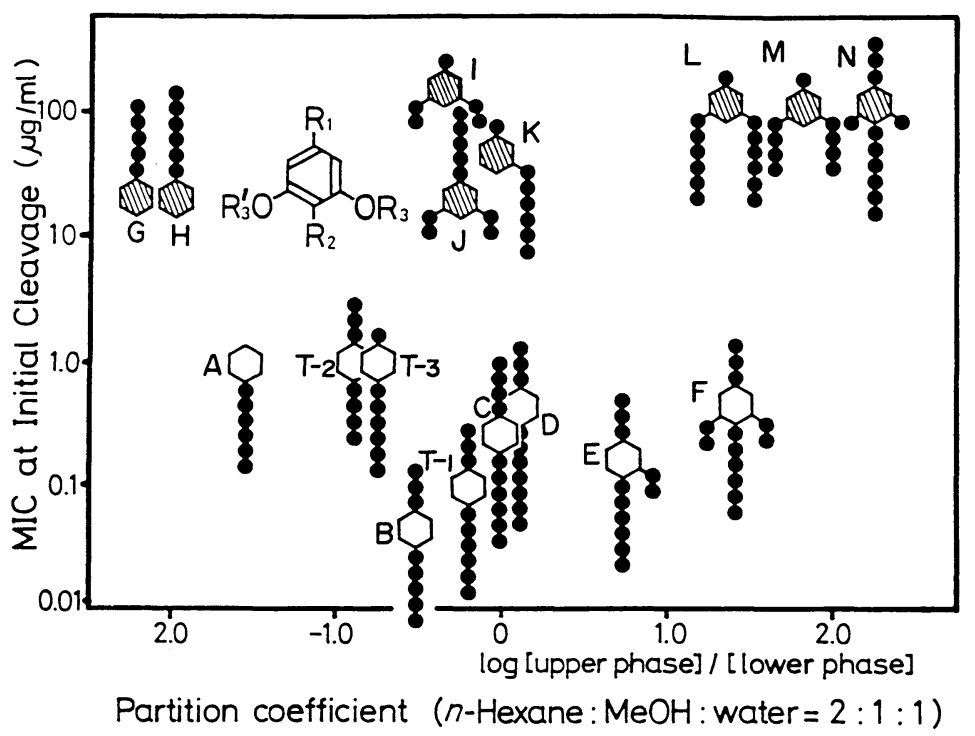

Fig. 12. Partition coefficients of T-1, T series and the derivatives Structure B, and E stand for Compound 8 (most active form) and T-1 monoacetate, respectively. Open hexagon $(\bigcirc)$ shows active, while closed hexagon $(\mathbb{Q})$ shows inactive $(50)$. 
optimum structure with respect to the balance between hydrophobicity and hydrophilicity. All the dimethylethers in the T series compounds showed no activity because of the higher hydrophobicity than that of the original compounds. In order to induce barrel-shaped spindles, we found that at least one phenolic hydroxy group must be free or unprotected. T-3, possessing a shorter alkyl group (methyl) at C-5, was also a potential inducer of barrel-shaped spindles. A compound lacking a side chain at C-5 retained considerable activity, whereas olivetol [11] and a newly synthesized compound [12] which does not possess a side chain at C-2, were inactive. This means that the substitution at C-5 was not the absolute necessity to express biological activity, while the presence of a large hydrophobic group at C-2 is essential, and an alkyl chain at C-5 exclusively holds the key role to enhance the membrane permeability of this compound into the cells. The relationship of molecular structure and the chemical efficacy of $T$-series and their derivatives were also analyzed on the basis of the partition coefficients (Fig. 12). All of active compounds revealed to possess the similar coefficients (29).

v). Curvularin: A molecule possess a T-1 -like efficacy. Recently, we found that the culture broth of a soil fungus Penicillium sp. 511, also induced small barrelshaped spindles in fertilized sea urchin eggs. Chromatographic separation afforded two active compounds, namely culvularin [13] and 8,9-E-dehydrocurvularin [14], $(27,30)$. In general, Curvularin also induced barrel-shaped spindles and arrested dividing eggs in metaphase. Growth of astral rays was markedly suppressed at the concentration of $2 \times 10^{-5} \mathrm{M}$. The presence of 1,3-benzenediol system and a large hydrophobic alkyl grouping is the notable structural similarity between the culvularin and $\mathrm{T}$ series. However, the $\mathrm{T}$ series compounds were ca. 20 times more effective than Curvularin, suggesting that the substitution position of functional groups as well as the total balance of hydrophobicity is a very important factor to exert activity. In order to enhance the activity, derivatization of Curvularin was attempted following the rationals and procedures to analyze the structure-activity relationships of $\mathrm{T}$ series compounds and their derivatives as described before.

vi). Structural similarities between the T-series compounds and curvularins. $\mathrm{T}-1$ monoacetate [15] was almost as effective as T-1 itself. When 3'-O-alkyl group of curvularin is overlapped with C-5 alkyl chain of T-1 monoacetate, and the carbonyl group at C-2 of curvularin with the acetylcarbonyl of T-1 monoacetate, the threedimensional structural model of 3'-O-alkylcurvularin can be superimposed with that of T-1 monoacetate (Fig. 13). It was expected that the derivatization of 3'-O-alkylcurvularin could give a desirable activity, and sure enough, 3'-O-ethylcurvularin [16] demonstrated a strong efficacy for suppressing the first cleavage of developing

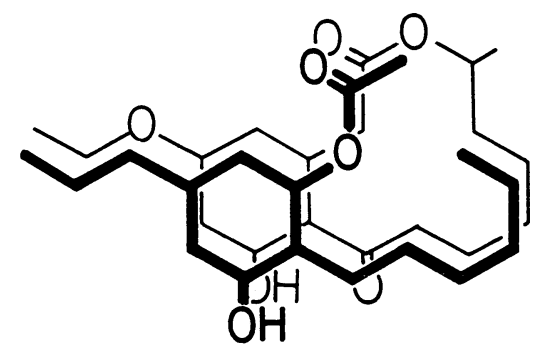

Fig. 13. Structure overlap of T-1 monoacetate [15] with 3'-O-ethylcurvularin. 
sea urchin eggs at a concentration of $1.5 \times 10^{-7} \mathrm{M}$. The level of chemical efficiency was almost identical to that of $\mathrm{T}-1$, which required the approximate concentration range of $2.0 \times 10^{-7} \mathrm{M} .3^{\prime}, 5^{\prime}-\mathrm{O}$-dimethylcurvularin [17] and $3^{\prime}, 5^{\prime}$-diacetylcurvularin [18] were less effective than the parent compound, although they both possessed the same unique activity. In the case of curvularin, the complete protection of two hydroxyl groups did not yield considerable loss of the molecular activity since the dimethylether and/or the acetate of curvularin still possess moderate lipophilicity. 5'-O-methyl-curvularin [19] showed stronger activity than curvularin, suggesting that the lipophilicity introduced in the vicinity of C-5 position increased the biochemical activity. Thus, we removed the carbonyl group at $\mathrm{C}-10$ position by hydrogenolysis and modified the molecule to 10-deoxodihydrocurvularin [20]. We found that this compound increased efficacy and inhibited the first cleavage of sea urchin eggs at a two-fold lower concentration than curvularin. It should be noted that these resorcinol derivatives all react with specific sites (i.e. MTOCs) in centrosomes and suppress the growth of asters as T-1 and its derivatives do (Fig. 14).

However, 8,9-E-dehydrocurvularin [14], which possesses a close structural resemblance with curvularin, induced minute-sized spindles and blocked the first cleavage in developing sea urchin eggs at a much lower concentration, $5.0 \times 10^{-6} \mathrm{M}$, compared to curvularin. Dehydrocurvularin, an extended conjugation system ( $\mathrm{Ph}$ $\mathrm{CO}-\mathrm{C}=\mathrm{C}-$ ) with a rich $\pi$ electron system, could provide favorable structural features and interact with tubulin molecules and disassembled microtubules. When this drug was applied at $35 \mathrm{~min}$ from fertilization, miniature spindles were formed and retained as long as $90 \mathrm{~min}$. When this drug $\left(5 \times 10^{-5} \mathrm{M}\right)$ was applied to sea urchin eggs $65 \mathrm{~min}$ after fertilization (eggs were about in metaphase), miniature spindles about $60 \%$ smaller in volume were induced at $70 \mathrm{~min}$ and arrested in

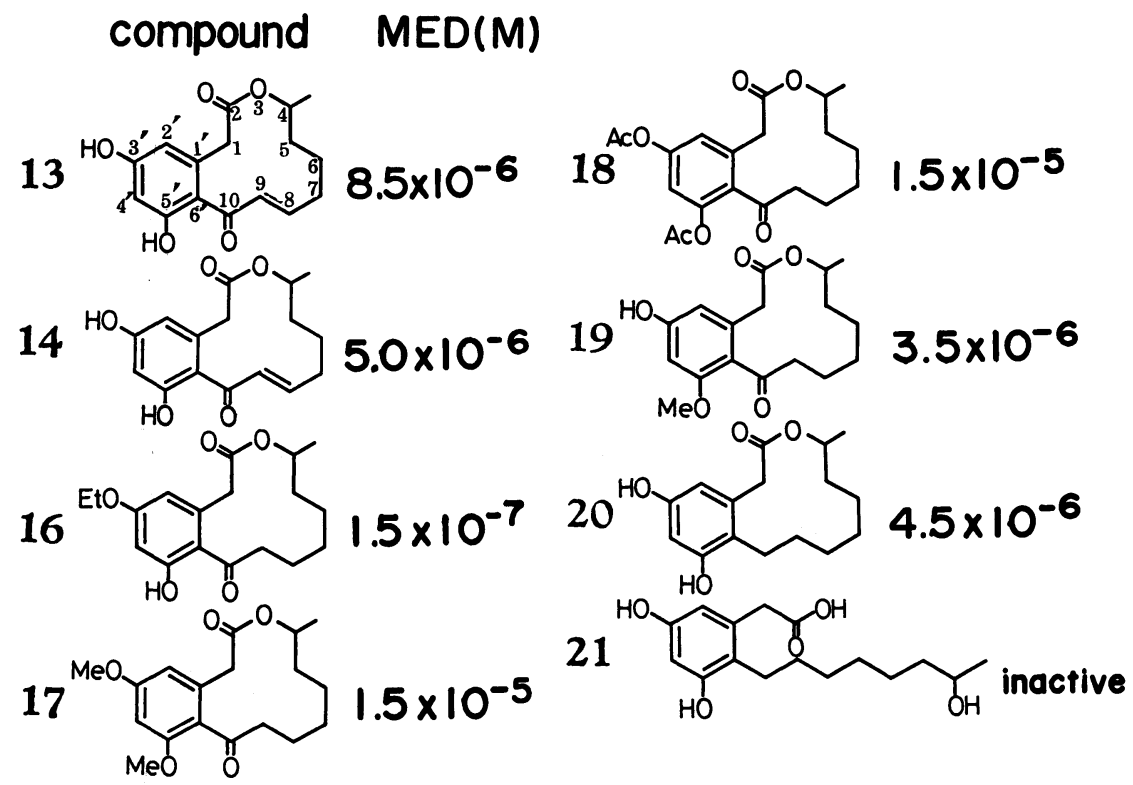

Fig. 14. Potency in barrel-shaped spindle induction of curvularin and the derivatives. MED(M): minimum effective dose. 
metaphase. This observation supports the idea that this drug effectively induces a partial depolymerization of spindle microtubules. However, curvularin did not induce miniature spindles at the same concentration $\left(5.0 \times 10^{-5} \mathrm{M}\right)$, though the birefringence of spindle asters are reduced.

Necessity for the lactone ring for the biochemical activity was examined by compound 21 , which was obtained by the alkali hydrolysis of $3^{\prime}, 5^{\prime}$-O-dibenzylcurvurlarin, followed by hydrogenolysis. This compound, however, had no activity because ring opening causes drastic polarity enhancement. We confirmed that the lactone must be intact to retain the molecular efficacy.

vii). TO series with stabilizing effects on spindle microtubules. Long term culture of Pseudomonas sp. 218 newly produced three metabolites together with the $\mathrm{T}-1$ series compounds. The new metabolites prolonged the mitotic process in first division of sea urchin eggs by ca. $30 \mathrm{~min}$. Spindles with strong birefringence were still observed at $90 \mathrm{~min}$ after fertilization when tzhe first cleavage is supposed to finish in the control egg. The three new active constituents were isolated and identified to be 2-hydroxy-3- $n$-hexyl-6-n-propyl-1,4-benzenediol [TO-1:22], 2-hydroxy-3$n$-butyl-6-n-propyl-1,4-benzenediol [TO-2:23], and 2-hydroxy-3- $n$-hexyl-6-methyl1,4-benzenediol [TO-3:24]. In a range of concentrations of $10^{-5}$ to $10^{-6} \mathrm{M}$, these compounds gradually slowed down the embryonic development and finally stopped it before them morula stage. A part of this inhibitory effect of the TO series compounds for sea urchin development could be due to the disturbance of the microtubular dissociation in spindles on time.

viii). Macbecin I with a unique overstabilizing effect on spindle microtubules. The analysis of the "structure-activity" relationship suggested that compounds possessing 1,4-benzoquinone system with long hydrophobic alkyl groups could exert a unique overstabilizing effect on spindle microtubules. Therefore, several antibiotics which possess similar structural features were examined and Macbecin I [25] was found to be the most effective in inducing an unusually large spindle and
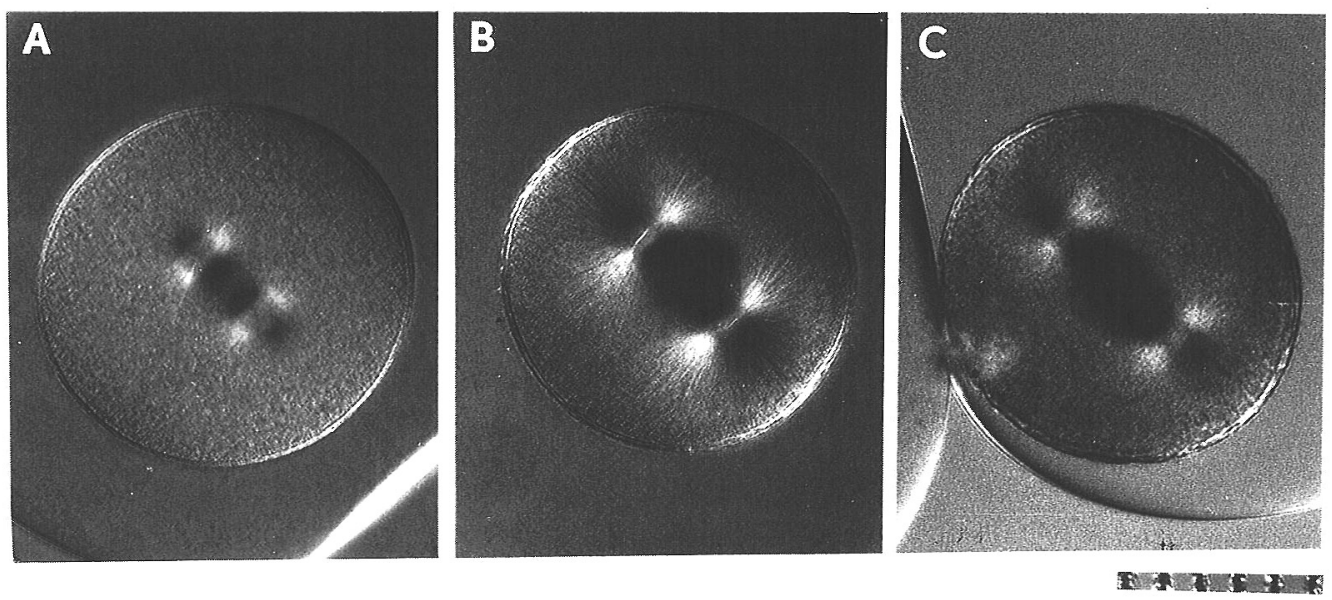

Fig. 15. Enhanced spindles with strong birefringence induced by mitotic arresters. Specimen: Hemicentrotus pulcherrimus. A; control, B; treated with Macbecin I $\left(8 \times 10^{-5} \mathrm{M}\right) 35 \mathrm{~min}$ after fertilization, $C$; treated with the ethylacetate extract of fungal broth $(20 \mu \mathrm{g} / \mathrm{ml} \mathrm{sea}$ water $)$. Polarization microscopy. Scale; $1 \mathrm{div} .=10 \mu \mathrm{m}$. 
overstabilizing it as shown in Fig. 15B. The volume of the mitotic spindle and its asters in Macbecin I treated eggs of $H$. pulcherrimus was 6 to 8 folds of the normal spindle and the measured retardation (BR) increased from the normal $3.7 \mathrm{~nm}$ to 8 $10 \mathrm{~nm}$. The state of metaphase arrest persisted more than one cell cycle and eggs rarely manged to divide. The effect of Macbecin I on the mitotic spindle is totally reversible and can be repeated a few times in the same cell. The Macbecin I dependent association reaction for the spindle in $C$. japonicus is completed within $\mathbf{3}$ min at $25^{\circ} \mathrm{C}$. The biological effect of Macbecin $\mathrm{I}$ is comparable to Taxol and in many ways is quite similar to the isotope effect of $\mathrm{D}_{2} \mathrm{O}$ which promotes tubulin polymerization both in vivo and in vitro (47).

However, in vitro bovine tubulin polymerization revealed that Macbecin I neither accelerated tubulin polymerization nor prevented microtubular dissociation. This

15 T-1 monoacetate<smiles>CCCCCCc1c(O)cc(CCC)cc1OC(C)=O</smiles>

22 T0-1<smiles>CCCCCCC1=C(O)C(=O)C(CCC)=CC1=O</smiles>

23 T0-2<smiles>CCCCC1=CC(=O)C(CCCC)=C(O)C1=O</smiles>

24 T0-3<smiles>CCCCCCC1=C(O)C(=O)C(C)=CC1=O</smiles>

25 Macbecine I

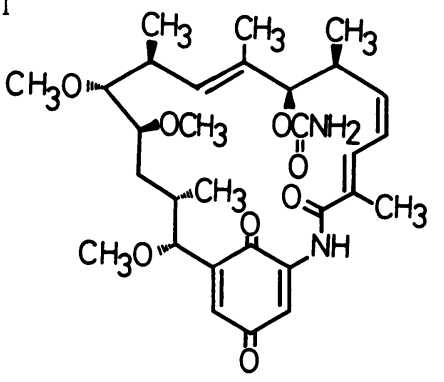

Fig. 16. Chemical structures of T-1 monoacetate, TO-1, TO-2, TO-3 and Macbecin I. 
compound was originally isolated from the broth of Nocardia $\mathrm{sp}$. as an antineoplastic drug and was known to possess the inhibitory effect on ciliogenesis in ciliated protozoa (62). However, the molecular basis of this chemical efficacy is not yet known. We believe that this unique effect of Macbecin I might cause the drastic increase of tubulin molecules in egg cytoplasm altering masked, reserved form to the polymerizable form. The mitotic process was generally greatly extended in sea urchin eggs treated with this drug. Chemical structures of Macbecin I, T-1 monoacetate, TO-1, TO-2 and TO-3 are illustrated in Fig. 16.

To compare the chemical efficiency, Taxol was applied to developing sea urchin eggs following the same time schedule as used for testing T-1, Curvularin and macbecin I. The microtubule stabilization effect of Taxol was almost the same as that of the TO series and much milder than that of Macbecin I. The overstabilization effect induced by Macbecin I is outstanding among the known chemicals tested so far. Therefore, the "overgrown" and "overstabilized" spindle with strong birefringence could be used as an indicator to survey new anticancer drugs (53).

Recently, we found that an ethylacetate extract obtained from the soil fungus broth induced huge spindles with well-grown asters in fertilized eggs of $H$. pulcherrimus (Fig. 15c) [30 or 31]. The chemical structure of this active constituent has not yet been determined. However, the compound has a good possibility to be classified as a new mitotic arrester, and the comparison of the molecular structure with Macbecin I would provide us with useful information on the mechanism of tubulin polymerization in living, dividing cells. The search for new mitotic arresters from microbial metabolites is continuing in our laboratory with the aim of finding reliable and effective molecular probes to solve the molecular bases of cell structure and function.

\section{Biological Effects of $T-1$}

As we reported earlier, T-1, its derivatives and curvularins react with spindle microtubules at the sub-micromolar level, and induce the barrel-shaped spindle in dividing sea urchin eggs. The barrel-shaped spindle is characterized as having (1) shortened pole to pole distance, (2) straightened spindle fibers with about even length, (3) the spread, discoidal polar regions and (4) small asters. Because spindle microtubules are presumably in a state of a dynamic equilibrium with tubulin molecules in the cytoplasm (13), we attempted to verify whether $\mathrm{T}-1$ could directly affect tubulin polymerization or not.

i). Effects of T-1 on tubulin polymerization in vitro. Tubulin was prepared from bovine brains with the temperature dependent cycles of assembly and disassembly, and then purified with DEAE-Sephacel column chromatography (16). Polymerization was initiated by adding $8 \%$ DMSO with various concentrations of $\mathrm{T}-1$, and monitored using Ostwald type viscometers at $37^{\circ} \mathrm{C}$.

$\mathrm{T}-1$ reduced both the initial rate and the final extent of polymerization proportionally to the increase of drug concentration. The equilibrium viscosity decreased to $30 \%$ of the control at $2 \times 10^{-4} \mathrm{M}$ of $\mathrm{T}-1$. When $\mathrm{T}-1$ was applied to microtubules in a steady state, viscosity decreased depending on the drug concentration. Electron micrograph showed that microtubules polymerized in the presence of the drug had no morphological change, and no notable shortening of microtubules was detected. Thus, the decreased viscosity in the presence of the drug was not due to the fragmentation of microtubules but due to the suppression of the polymerization reaction. These results indicated that $\mathrm{T}-1$ could inhibit microtubule polymerization 
in some way similar to mitotic poisons. However, the range of the effective doses for in vitro experiments was much higher than that for suppressing the cell division and/or for inducing the barrel-shaped spindle. Now a new question arises. Was the induction of barrel-shaped spindle directly mediated by the suppression of microtubule polymerization?

ii). Effects of T-1 on in vivo spindle assembly. To solve the above problem, effects of $\mathrm{T}-1$ on the spindle assembly in fertilized sea urchin eggs, Hemicentrotus pulcherrimus, were examined with a sensitive polarizing microscope. Figure 17 shows stabilized metaphase spindles of the first division in eggs developed with various concentrations of T-1. The modified isolation medium of Sakai et al. (1977) was used for spindle stabilization (16). As shown in Fig. 17, the barrel-shape of spindles became more obvious with the increase in drug concentration. The pole to pole distance of the spindle decreased to $45 \%$ of its original size in $4 \times 10^{-7} \mathrm{M}$ of T1. Spindle poles were spread completely and the typical barrel-shape was constantly induced. Further shortening of pole to pole distance hardly occurred by increasing drug concentration, but the width of spindle tended to decrease; for example, it reduced to $85 \%$ of the control at $4 \times 10^{-6} \mathrm{M}$. These observations indicated that the most efficient effect of $\mathrm{T}-1$ on the spindle morphology is achieved at $4 \times 10^{-7} \mathrm{M}$.
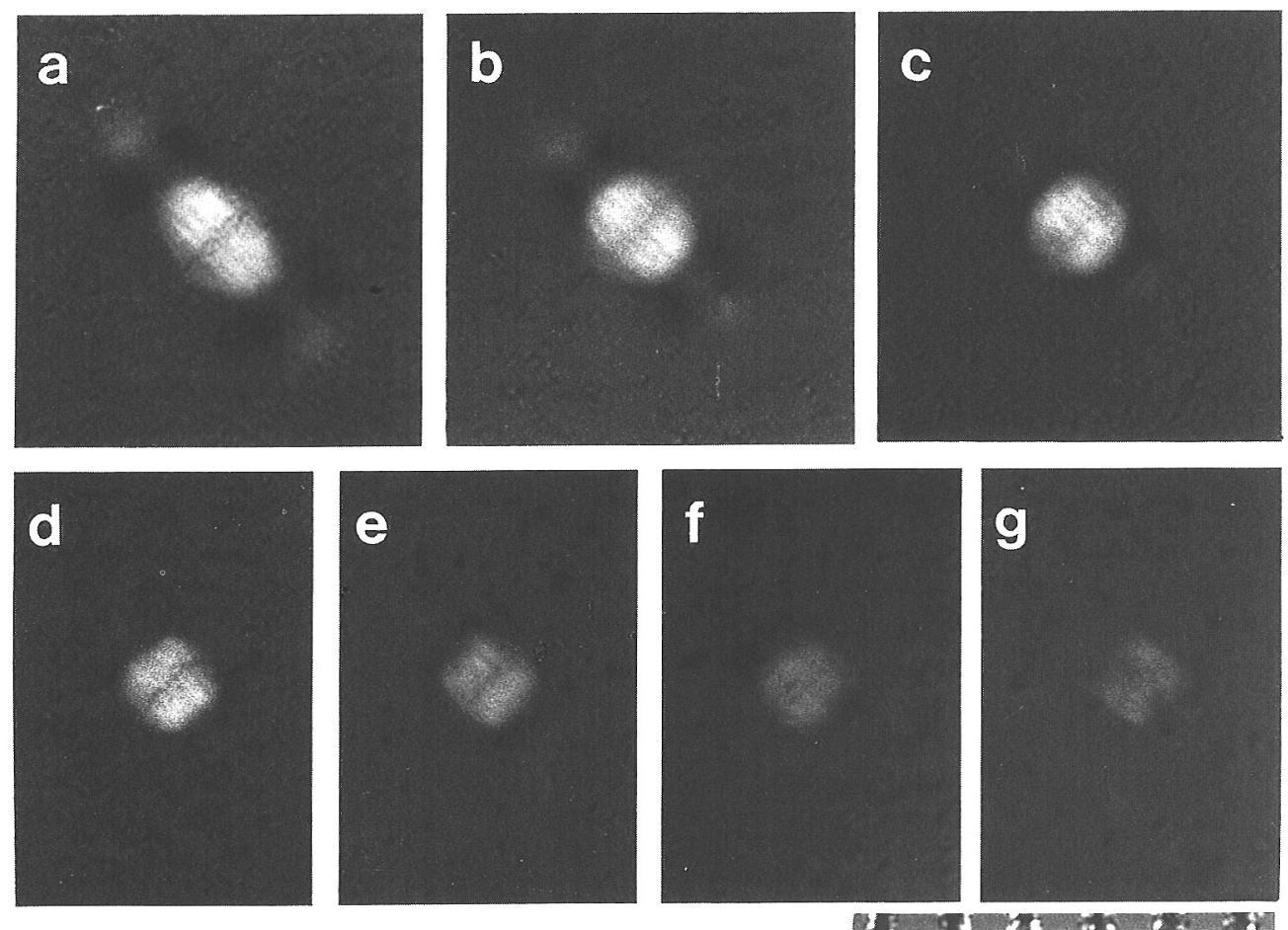

Fig. 17. The dose dependent effect of T-1 on spindles in metaphase of $H$. pulcherrimus eggs at first devision. $30 \mathrm{~min}$ after fertilization, eggs were transfered to ASW containing various concentrations of T1 and allowed to develop. At metaphase ( $70 \mathrm{~min}$ after the fertilization), spindles were stabilized. T-1 concentrations: a, control; b, $1.3 \times 10^{-7} \mathrm{M} ; \mathrm{c}, 2.1 \times 10^{-7} \mathrm{M} ; \mathrm{d}, 4.2 \times 10^{-7} \mathrm{M} ; \mathrm{e}, 8.4 \times 10^{-7} \mathrm{M} ; \mathrm{f}, 2.1 \times 10^{-6}$ $\mathrm{M} ; \mathrm{g}, 4.2 \times 10^{-6} \mathrm{M}$; respectively. Scale; $1 \mathrm{div} .=10 \mu \mathrm{m}(15)$. 
Because the spindle birefringence reflected directly the amount of microtubules oriented within the spindle (49), spindle birefringence was measured to quantify the effects of the drug on the assembly of spindle microtubules. We found that spindle birefringence decreased when the T-1 concentration increased. Birefringence, which was estimated to be around $4 \mathrm{~nm}$ in control at $19^{\circ} \mathrm{C}$, decreased slightly at a concentration of $4 \times 10^{-7} \mathrm{M}$. In general, the decrease of spindle birefringence was inversely proportional to the increase in T-1 concentration up to $4 \times 10^{-6} \mathrm{M}$ without altering the spindle morphology. No spindle was formed in the eggs treated with more than $1 \times 10^{-5} \mathrm{M} \mathrm{T}-1$, suggesting strong disruption effect on the microtubule assembly in living cells. We confirmed that the effective range of T-1 concentration for in vivo spindle assembly is rather narrow, and the alteration of the spindle morphology by T-1 might be independent of the suppression of microtubule assembly.

When sea urchin eggs were treated with an appropriate period by low concentration of T-1, anaphase could be induced in these barrel-shaped spindles which were arrested in metaphase in a prolonged period. Length of time in metaphase-arrest vs. $\mathrm{T}-1$ treatment was hard to determine due to so many factors being involved. However, chromosomes could move with a very slow pace. Because the spindle poles were already spread in metaphase, anaphase pole separation was hardly recognizable. Also, the elongation of half spindles which commonly occurred in mid- to late-anaphase in dividing sea urchin eggs were not prominent. Daughter nuclei were formed but no cleavage furrow was observed. Figure 18 shows the examples of barrel-shaped spindles in anaphase in stabilized eggs of $H$. pulcherrimus.

iii). Modification of spindle by $T-1$. (a) Pulse treatment of unfertilized eggs with T-1. Barrel-shaped spindle could also be induced by pulsing unfertilized sea urchin eggs with $T-1$ (17). When eggs were pretreated with various concentrations of $\mathrm{T}-1$ and fertilized at intervals ranging from five to $240 \mathrm{~min}$, barrel-shaped spindles always assembled in the first division. For instance, five min exposure to $4 \times 10^{-7} \mathrm{M}$ of T-1 was sufficient to modify the spindle assembly in later. Spindle birefringence also decreased proportionally to the increase in drug concentration for pulsing (Fig. 19). However, when eggs were fertilized 60 to $240 \mathrm{~min}$ after a pulse treatment, for example $2 \times 10^{-6} \mathrm{M}$ of T-1, the decrease of birefringence was less apparent. However, when eggs were left unfertilized for more than $240 \mathrm{~min}$, spindle birefringence attained the level of the control. Although the birefringence recovered in accordance with the increase of time interval between pulse treatment and fertilization, spindles in first division seldom reverted to the normal form.

Barrel-shaped spindles were induced when eggs were pretreated with appropriate concentrations of $\mathrm{T}-1$ for more than five min, and the microtubule density within the spindle was decreased depending on the concentration of T-1 and the length of treatment. Because the number of microtubules could be restored by increasing the interval between the pulse treatment with $\mathrm{T}-1$ and fertilization, we believe the $\mathrm{T}-1$ effect on the disturbance of microtubule assembly in vivo could be reversible. However, T-1 dependent induction of barrel-shaped spindles was quite difficult to reverse. Based on these results, we assume that $T-1$ is tightly bound to some regulatory factor(s) for spindle assembly, which might be present in unfertilized eggs, and thus modifies the spindle shape.

(b) $\mathrm{D}_{2} \mathrm{O}$ effect on the barrel-shaped spindle. As described in chapter II, $\mathrm{D}_{2} \mathrm{O}$ promotes spindle microtubule assembly, and this $\mathrm{D}_{2} \mathrm{O}$-dependent reaction is totally reversible and can be repeated $(48,50,52)$. If the reduction of microtubule assembly caused by T-1 was a necessary step for the barrel-shaped spindle induction, then the 


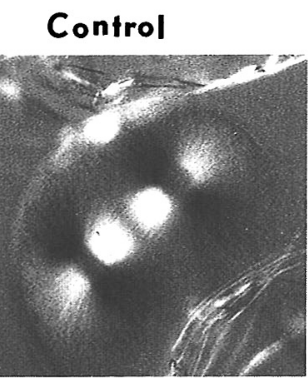

\section{T- immersion}
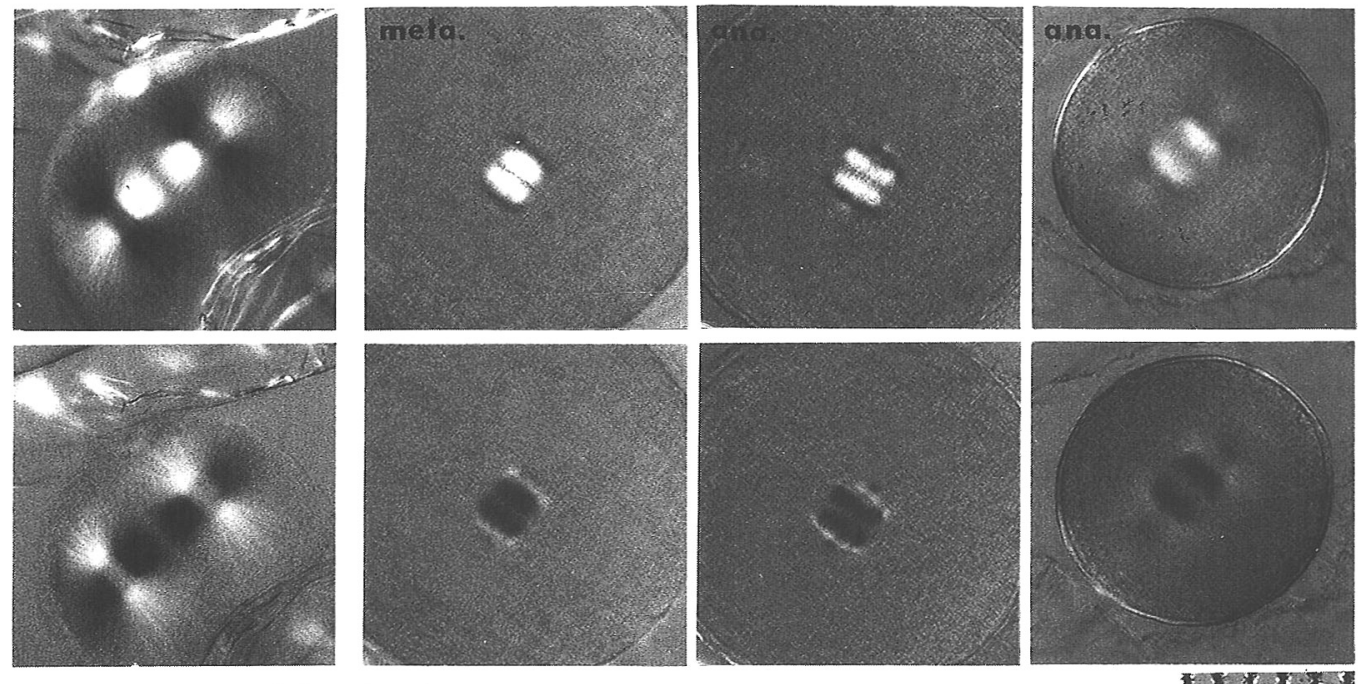

(Hemicentrotus pulcherrimas)

Fig. 18. Barrel-shaped spindles in early to late anaphase induced in $H$. pulcherrimus eggs with low concentration of T-1 $\left(4 \times 10^{-7} \mathrm{M}\right)$. Control spindle is shown in left side with white and black compensation. Polarization Microscopy. Scale, 1 div. $=10 \mu \mathrm{m}$.

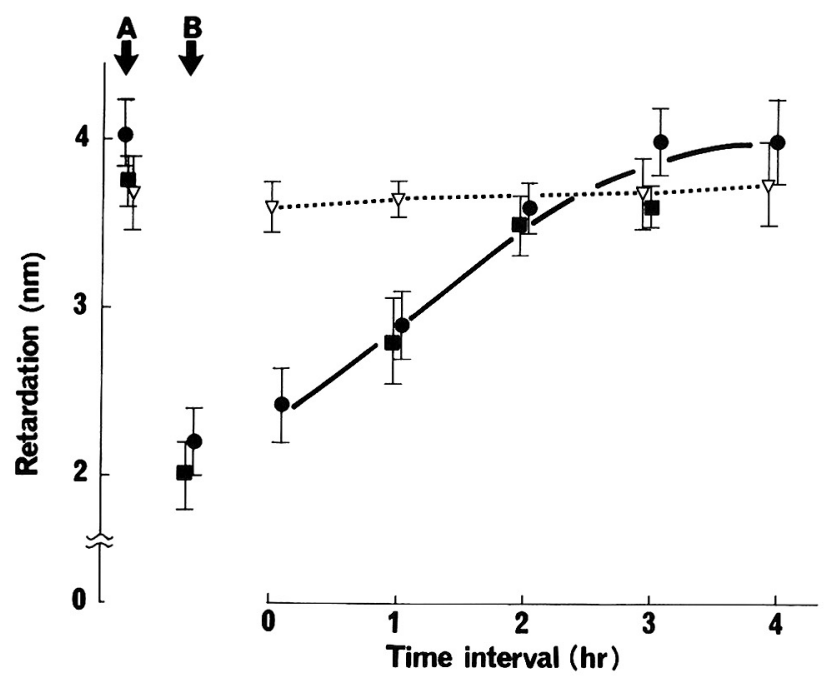

Fig. 19. BR recovery in B-spindles induced by pulse-treating eggs of $H$. pulcherrimus with T-1. The points below arrow A represent the BR of control spindle and those below arrow B, the BR of B-spindle induced by T-1 applied after the syngamy formation. Different symbol shapes correspond to the different batches of eggs. The $\mathrm{x}$-axis indicates the length of the interval between $\mathrm{T}-1$ treatment and fertilization. The $y$-axis indicates the amount of BR in the center of the half spindle. The T-1 concentration used was $4.2 \times 10^{-7} \mathrm{M}$ (open symbols) or $2.1 \times 10^{-6} \mathrm{M}$ (closed symbols). The sample number for each point ranges from 18 to 20 eggs (16). 

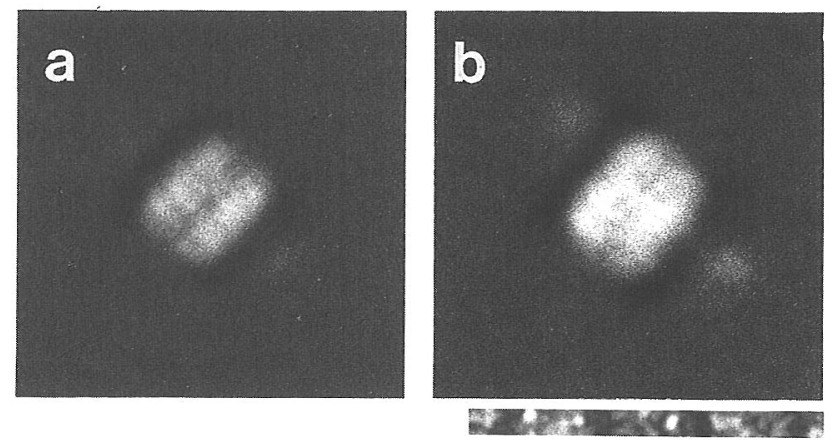

Fig. 20. Effect of $30 \% \mathrm{D}_{2} \mathrm{O}$ on B-spindle in eggs of $\boldsymbol{H}$. pulcherrimus. a: AB-spindle induced with $2.1 \times 10^{-6}$ M T-1 applied after pronuclear fusion. (b) AB-spindle treated with $30 \% \mathrm{D}_{2} \mathrm{O}$ for two min in metaphase. Note that the length and width of the B-spindle are increased but that the structure of spindle is not at all restored to the original form of untreated spindle. Scale; 1 div. $=10 \mu \mathrm{m}(16)$.

modification of spindle structure should be interrupted and restored by applying $\mathrm{D}_{2} \mathrm{O}$. Thus, we applied $\mathrm{D}_{2} \mathrm{O}$ to $\mathrm{T}-1$ treated eggs of sea urchin (17).

When fertilized eggs were kept in $30 \% \mathrm{D}_{2} \mathrm{O}$ sea water, the barrel-shaped spindle clearly responded to $\mathrm{D}_{2} \mathrm{O}$ and increased its birefringence. As shown in Fig. 20, both the length and the width of the barrel-shaped spindle increased without changing the ratio of length vs. width. The length of astral fiber also increased and the overall shape of the spindle became more spherical. Obviously, the enhancement of spindle microtubule assembly by the presence of $\mathrm{D}_{2} \mathrm{O}$ was responsible for these changes; however, the normal shape of the spindle was never restored by $\mathrm{D}_{2} \mathrm{O}$ which enhanced the microtubule polymerization. Applying $\mathrm{D}_{2} \mathrm{O}$ to $\mathrm{T}-1$ treated eggs neither modified the spread state of the spindle poles nor improved the reduced length to width ratio. Delayed anaphase sequences caused by T-1 treatment showed no sign of acceleration or retardation including the chromosome movement. Results clearly indicate that the positive modification of spindle microtubule assembly does not effect the alteration of spindle morphology caused by T-1.

iv). Fine Structure of the Barrel-Shaped Spindle. (a) Survey with light microscopes. Isolation medium designed by Mazia and his co-workers $(36,42)$ worked well to preserve the framework of spindles in various sea urchin eggs, and allowed us to investigate the centrosomal separation and modification.

Usually, centrosome in a normal half spindle in metaphase can be seen as a dark spot in the center of the aster under a phase contrast microscope. Centrosomal separation can be induced in developing sea urchin eggs by treating them with $10^{-1}$ $M$ of $\beta$-mercaptoethanol (35). In this case, the centrosomal split and the separated daughter centrosomes could be observed as two dark spots located in the spread polar regions of the spindle. Assuming the T-1 dependent barrel-shaped spindle induction was caused in a similar manner, we should be able to detect the presence of two dark dots in each pole of the barrel-shaped spindle.

However, contradicting this assumption, we found no structure corresponding to the images of split centrosomes in the isolated, barrel-shaped spindle induced by T1. In fact, we always found a few strands with dark beads which were aligned parallel to the metaphase plate and distributed in a plane in the spread polar regions 

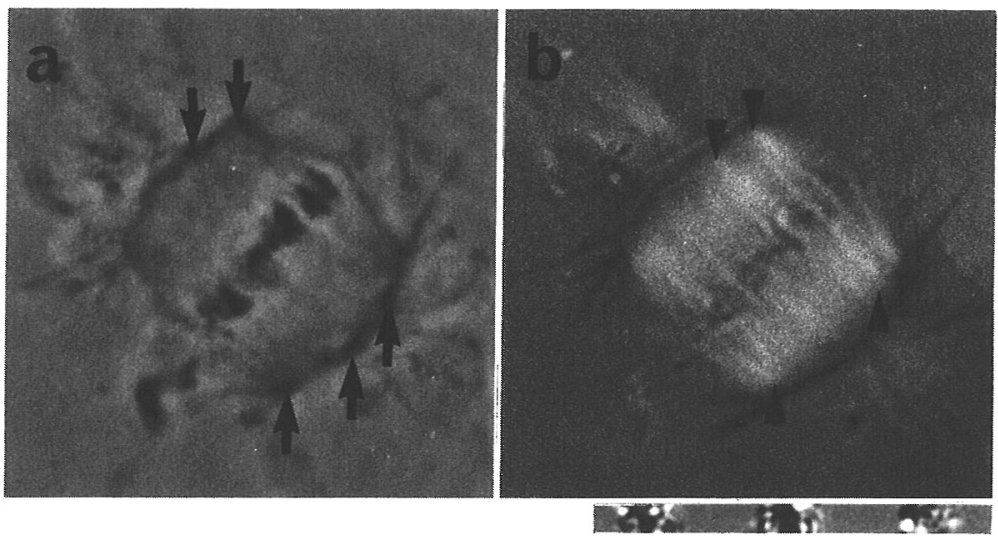

Fig. 21. An isolated B-spindle induced with $4.2 \times 10^{-7} \mathrm{M}$ of T-1. a: Phase contrast micrograph. Arrows indicate the dark beads which may correspond to MTOCs. b: Polarizing micrograph. Arrowheads indicate spindle fibers with strong birefringence terminated at the dark beads. Birefringent fibers of the astral microtubules are also observed as the dark contrast fibers generated from the beads perpendicular to the spindle axis. Scale; $1 \mathrm{div} .=10 \mu \mathrm{m}(17)$.
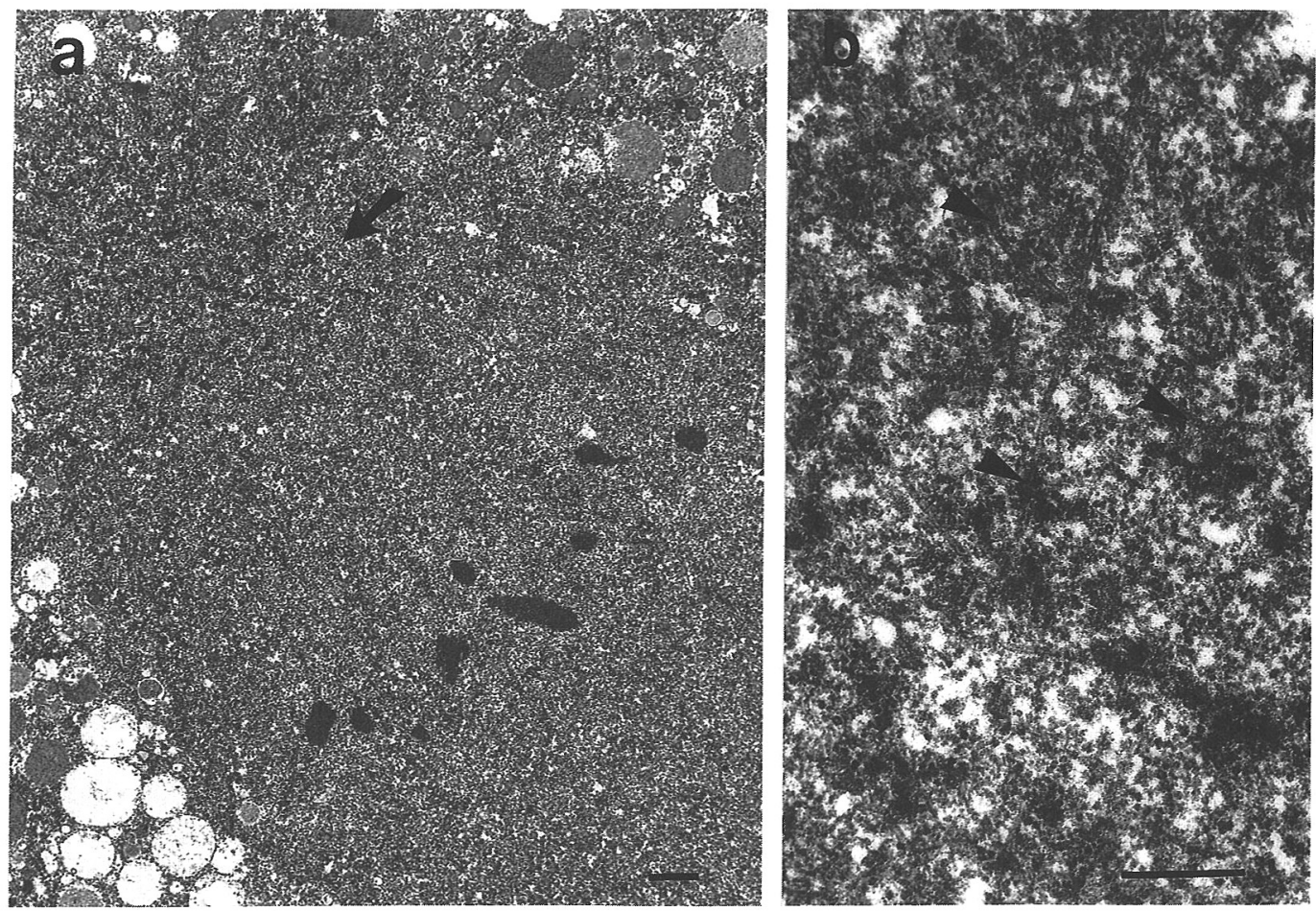

Fig. 22. Electron micrographs of a B-spindle induced by $8 \times 10^{-7} \mathrm{M} \mathrm{T}-1$ in an egg of $H$. pulcherrimus. a: A half spindle in early anaphase at low magnification. Note the electron dense materials dispersed at the polar region perpendicular to the axis of the B-spindle (indicated by an arrow). bar $=1 \mu \mathrm{m}$. (b) high magnification of the polar region in Fig. 22a. Arrowheads indicated MTOCs. Bar $=0.5 \mu \mathrm{m}(17)$. 
(Fig. 21). Because birefringent spindle fibers were terminated at these dark beads, these dense regions could correspond to the microtubule organizing centers (MTOCs) which were formerly tightly associated with centrosomes but dispersed by the treatment with T-1. Birefringent fibers in poles which run perpendicular to the spindle axis were dispersed astral rays. These observations suggested that $\mathrm{T}-1$ did affect centrosomes directly and altered the distribution pattern of MTOCs during spindle assembly. We believe the barrel-shaped spindles induced by $\mathrm{T}-1$ is quite different compared with spindles organized after the mercaptoethanol treatment even though their similar appearance (16).

(b) Electron microscopy. Alteration of the spindle configuration by T-1 was further examined by the electron microscope (17). The fixation technique developed by Hirano et al. (1984) in our laboratory gave us improved preservation of the spindle ultrastructure as well as the associated membranous components in dividing sea urchin eggs. As shown in Fig. 22a, electron dense material always appeared in the polar regions of the spindle. However, this material did not form a compact aggregate in T-1 treated spindles as it does in the poles of control metaphase spindles. The distribution of this material was rather dispersed and localized perpendiculer to the spindle axis. This material was composed of aggregated clusters of tiny granules. Many microtubules were terminated on them and appeared to fan out from them in various directions, indicating that they could be the MTOCs (Fig. 22b). In a series of cross sections of the polar region of a barrel-shaped metaphase spindle, we confirmed that the MTOCs dispersed and formed a disc.

Attempts were also made to observe isolated barrel-shaped spindles. The majority of spindle microtubules were radially oriented in the polar regions of isolated spindles. Many short and fragmented microtubules were also seen in this region. A number of minute filamentous bridges which appeared to connect neighbouring microtubules were seen in the polar region. Many granules commonly observed in sections of whole eggs were probably lost during the isolation procedure of spindles. The filamentous bridges, which could be the residual skeletal components of the centrosome, remained throughout the isolation procedure. We thought this "bridge-rich region" to be the modified centrosome of the isolated spindle. The centrosome appeared to be in a spread and rather flattened form and oriented perpendicular to the spindle axis. The centriolar pairs were always located in the middle of the centrosomal area. We feel that the segregation of the centrosome may not be caused by the T-1 dependant induction of the barrel-shaped spindle.

A three dimensional reconstruction of an isolated barrel-shaped spindle by superimposing serial sections clearly showed that the centrosome had a flat, spread appearance (Fig. 23). Although the components of centrosome preserved in isolated spindle did not have the same appearance as in the sections of preserved whole eggs, we could obtain ultrastructural evidences for the dispersed state of the MTOCs in barrel-shaped spindles. Because the polar regions on electron micrographs appeared to be consistent and in good agreement with the results obtained from light microscopy, we believe that the alteration of the distribution pattern of the MTOCs could result from the dispersion of the pericentriolar materials, granules and associated substances by the chemical influence of $\mathrm{T}-1$.

v). T-1 as the molecular probe to examine centrosome. In the case of the spindle of a plant cell (54), high concentrations of T-1 mainly affected the spindle birefringence. Any significant alteration did not occur in the polar region, even with higher concentrations of $\mathrm{T}-1$. These effects are ascribed to the absence of the cen- 


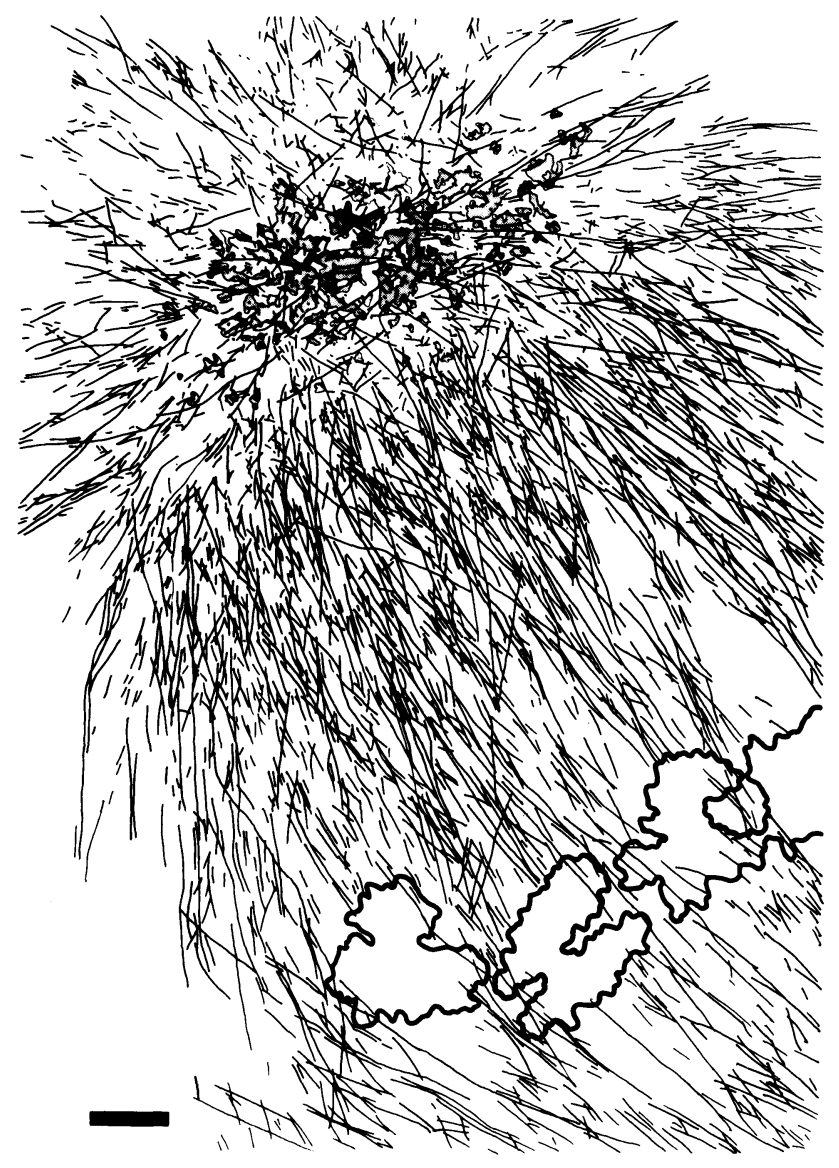

Fig. 23. Three-dimensional reconstruction of a half B-spindle at the onset of anaphase. Microtubules, chromosomes and bridge-rich regions were traced through four adjacent sections. bar $=1 \mu \mathrm{m}$ (17).

trosome in plant cells, and T-1 could not modify the spindle configuration. Only the secondary effect of the drug, the suppression of microtubule assembly, could be detected. Indeed, the T-1 induced change in the plant spindle could be reversed by washing, suggesting that $\mathrm{T}-1$ influenced only the spindle microtubule assembly. Based on these data, we conclude that T-1 affected specifically the MTOCs of the centrosome.

The poles of acentriolar spindles in mouse oocytes and eggs were spread out, and the spindles were typically barrel-shaped (53). In contrast, the centrosomes of normal spindle in sea urchin eggs are more compact. We believe that one of the roles of centrioles may be to gather pericentriolar materials into a restricted area, thus forming and maintaining a compact shape of spindle in metaphase. Although centrioles were always located in the middle of the centrosome in barrel-shaped spindles, as they are in control spindles, the morphology of barrel-shaped spindle and with dispersed and flattened centrosomes resembled phenomenologically that of mouse oocytes or mouse eggs. In other words, the centrosome in T-1 treated cells might behave as if centrioles were absent in their center. For these reasons, we suggest that 
centrioles in barrel-shaped spindle could not perform the role of proper kinetic centers for spindle assembly, and could not gather the MTOCs during metaphase due to the influence of $\mathrm{T}-1$.

The centrosome is considered to be a kinetic organelle which governs the shape of the mitotic apparatus during cell division (37). However, we still have little evidence to understand the molecular basis of the modification of the centrosomal structure. T-1 may irreversibly change the distribution pattern of the kinetic centers on which microtubules associate. Thus, we believe that T-1 will be uniquely useful for examining the molecular basis of the physiology of the centrosome and of what determines spindle structure and function. We suggest that $\mathrm{T}-1$ could bind to some regulatory factor(s) that control the fine structure of the centrosome, and that the drug alters the overall morphology of the spindle. One of our next goals is to identify and characterize the biological effect of T-1 with both biochemical and physiological aspects.

Acknowledgement. This work was supported partly by Grants-in-Aids for Scientific Research provided from the Ministry of Education, Science and Culture of Japan. Numbers are: Grant-in-Aid for General Scientific Research, 60480020, and Grant-in-Aid for Co-operative Research 59380026, which are awarded to H. Sato. Sato also partly supported from the Grant-in-Aid for Co-operative Research numbered as, 58340042, 59390006, 61304008. A. Kobayashi supported by Grant-in-Aid for General Scientific Research, numbered as, 58560136, 59560127 and 63560130. T. J. Itoh supported by Grant-inAid for Encouragement of Young Scientists, 61790232.

We wish to extend our sincere thanks to faculties and staff members in Sugashima Marine Biological Laboratory for their kind cooperations and assistance provided to us during the present work.

We thank to Drs. S. Tanida, Y. Nakao, E. Higashide and M. Yoneda of the Microbiological Research Laboratories, Central Research Division, Takeda Chemical Industries, for supplying us Macbecin I and Maytansine.

We are also grateful to Drs. K. Kawazu and K. Koshimizu for their valuable advice and encouragement for our research, and Drs. K. H. Kato and M. Fukumoto for their allowance to use their facilities concerning electron microscopy.

\section{REFERENCES}

1. Bajer, A. and J. Molé-Bajer. Spindle dynamics and chromosome movement. in "Int. Rev. Cyto. Suppl. 3", eds. G.H. Bourne and J.F. Danielli, pp. 1-271. Academic Press, New York, 1972

2. Bragg, W.L. and A.B. Pippard. The form birefringence of macromolecules. Acta Crystallogr. Sect. B. Struct. Crystallogr. Chem. 6, 865-867, 1953

3. BRYAN, J. and H. Sato. The isolation of the meiosis I spindle from the mature oocyte of Pisaster ochraceus. Exp. Cell Res. 59, 371-378, 1970

4. Carolan, R.M., H. Sato and S. InouÉ. A thermodynamic analysis of the effect of $\mathrm{D}_{2} \mathrm{O}$ and $\mathrm{H}_{2} \mathrm{O}$ on the mitotic spindle. Biol. Bull. 129, 402, 1965

5. DeBrabander, M., R. Geuens, R. Nuydens, R. Willebrords and J. DeMey. Taxol induces the assembly of free microtubules in living cells and blocks the organizing capacity of the centrosomes and kinetochores. Proc. Natl. Acad. Sci. USA 78, 5608-5612, 1981

6. Dustin, P. (ed.) Microtubules. Springer-Verlag, Belrin/Heidelberg/New York. 1984

7. Farell, K.W., M.A. Jordan, H.P. Miller and L. Wilson. Phase dynamics at MT ends: the coexistence of dynamic instability and treadmilling. J. Cell Biol. 104, 1035-1046, 1987

8. Hill, T.L. and Y.-D. Chen. Phase changes at the end of a microtubule with a GTP cap. Proc. Natl. Acad. Sci. U.S.A. 81, 5772-5776, 1984

9. Hirano, K.-I., M. Masuda and H. Sato. Ultrastructral study of asters induced by microinjection with sperm centriolar fraction in sea urchin eggs. Develop. Growth and Differ. 26, 435-444, 1984

10. Houston, L.L., J. Odell, Y.C. LeE and R.H. Himes. Solvent isotope effects on microtubule polymerization and depolymerization. J. Mol. Biol. 87, 141-146, 1974 
11. Ikegami, S., Y. Kawada, Y. Kimura and A. Suzuki. A rapid and convenient procedure for the detection of inhibitors of DNA synthesis using starfish oocytes and sea urchin embryos. Agric. Biol. Chem. 43, 161-166, 1979

12. Inoué, S. and M.F. Morales. Motility of cilia and the mechanism of mitosis. Rev. Mod. Phys. 31, 402-408, 1959

13. INOUÉ, S. and H. SATo. Cell motility by labile association of molecules. The nature of mitotic spindle fibers and their role in chromosome movement. J. Gen. Physiol. 50, 259-292, 1967

14. Inoue, S. and R. Stephens (eds.) Molecules and Cell Movement. Soc. Gen. Physiol. Ser. 30, Raven Press, New York, 1975

15. Iтон, T.J. and H. SATo. The effects of duterium oxide $\left({ }^{2} \mathrm{H}_{2} \mathrm{O}\right)$ on the polymerization of tubulin in vitro. Biochim. Biophys. Acta 800, 21-27, 1984

16. Ітон, T.J. H. Sato and A. KoвAYASH. T-1 dependent barrel-shaped spindle induction in the sea urchin eggs and the role of T-1 in microtubule assembly. Zool. Sci. 3, 255-264, 1986

17. Iтон, T.J., H. Sato and A. Kobayashi. Examinations of spindle structure modified by T-1, the mitotic arrester. Zool. Sci. 4, 265-276, 1987

18. Johnson, K.A. and G.G. BorisY. Thermodynamic analysis of microtubule self-assembly in vitro. J. Mol. Biol. 133, 199-216, 1979

19. KAHLIL, M.T.M. and M.A. LAUfFer. Polymerization-depolymerization of tobacco mosaic virus protein. X. Effects of $\mathrm{D}_{2} \mathrm{O}$. Biochemistry 6, 2474-2480, 1967

20. Kawada, K., Y. Kimura, K. Katagiri, A. Suzuki and S. TAmura. Isolation of Aphidicolin as a root growth inhibitor from Haziella entomophilla. Agric. Biol. Chem. 42, 1611-1612, 1978

21. Kirschner, M. and T. Mitchison. Beyond self assembly: From microtubules to morphogenesis. Cell 45, 329-342, 1986

22. Kobayashi, A. and K. Koshimizu. Cytotoxic effects of breaken fern constituents, pterosins, on sea urchin embryos and a celiate. Agric. Biol. Chem. 44, 393-398, 1980

23. Kobayashi, A., A. Takemura, K. Koshimizu, H. Nagano and K. Kawazu. Candidusin A and B: New p-terphenyls with cytotoxic effects on sea urchin embryos. Agric. Biol. Chem. 46, 585-589, 1982

24. Ковау ASH, A. Mitotic arresters which regulate microtubule assembly. Actinomycetologica (Tokyo) 45, 4-11, 1984

25. KоваYASHI, A. Naturally occuring antimitotic compounds. kagaku-to-Seibutsu 23, 162-175 (in Japanese), 1985

26. Kobayashi, A., T. Hino, K. Uneyama and K. Kawazu. Chemical studies on microtubule assembly regulators of microbial origin. 27th Symposium on the chemistry of natural products, symposium papers, pp. 343-350 (in Japanese), 1985a

27. Kobayashi, A., A. Takemura, K. Koshimizu and K. Kawazu. p-Terphenyls with cytotoxic activity toward sea urchin embryo. Agric. Biol. Chem. 49, 867-868, 1985b

28. Kobayashi, A. Screening for cell proliferation inhibitors using sea urchin embryo assay system and their chemical structures. Nippon Nogeikagaku Kaishi, 60, 725-735 (in Japanese), 1986a

29. Kobayashi, A. The mitotic inhibitors. in "Molecular Design of Bioactive Compounds". eds. H. Yoshioka and K. Shudo, Soft Science Press, Tokyo, pp. 153-171, 1986b

30. Kobayashi, A., T. Hino, S. Yata, T.J. Itoh, H. Sato and K. KaWazu. Unique spindle poisons, curvularin and its derivatives, isolated from Penicillium species. Agric. Biol. Chem. 52, 31193123,1988

31. Kobayashi, A., T. Kawasaki and K. KawazU. Fungal metabolites which induce unique-shaped spindles in sea urchin dividing eggs. Annual Meeting of Agricultural Chemistry (Tokyo), Abstracts, p. 736 (in Japanese), 1987

32. KRESheCK, G.C., H. Schneider and H.A. Scheraga. The effect of $\mathrm{D}_{2} \mathrm{O}$ on the thermal stability of proteins. Thermodynamic parameters for the transfer of model compounds from $\mathrm{H}_{2} \mathrm{O}$ to $\mathrm{D}_{2} \mathrm{O}$. J. Phys. Chem. 69, 3132-3144, 1965

33. LAUfFER, M.A. Entropy-driven processes in biology. Springer-Verlag, New York, 1975

34. LEE, J.C. and S.N. TIMASHEFF. In vitro reconstruction of calf brain microtubules: Effects of solution variables. Biochemistry 16, 1754-1764, 1977

35. Mazia, D., P.J. Harris and T. Bibring. The multiplicity of the mitotic centers and the timecourse of their duplication and separation. J. Biophys. Biochem. Cytol. 7, 1-20, 1960

36. Mazia, D., N. Paweletz, G. Sluder and E.M. Finze. Cooperation of kinetochores and pole in 
the establishment of monopoler mitotic apparatus. Proc. Natl. Acad. Sci. USA 78, 377-381, 1981

37. Mazia, D. Centrosomes and mitotic poles. Exp. Cell Res. 153, 1-15, 1984

38. Mitchison, T. and M. Kirschner. Dynamic instability of microtubule growth. Nature (Lond) 312, 237-242, 1984

39. Nagao, H., S. Hirai, K. Okano and S. Ikegami. Achromosomal cleavage of fertilized starfish eggs in the presence of aphidicolin. Develop. Biol. 85, 409-415, 1981

40. Nishida, E., S. Maekawa and H. SaKai. Kinetic and thermodynamic analyses of outer doublet tubulin polymerization. J. Biochem. 93, 1021-1026, 1983

41. Olmsted, J.B. and G.G. Borisy. Characterization of microtubule assembly in porcine brain extracts by viscometry. Biochemistry 12, 4282-4289, 1973

42. Paweletz, N., Mazia, D. and E.M. Finze. The centrosome cycle in the mitotic cycle of sea urchin eggs. Exp. Cell Res. 152, 47-65, 1984

43. Remillard, S. and L.I. Rebhun. Antimitotic activity of the potent tumor inhibitor Maytansine. Science, 189, 1002-1005, 1975

44. Robinson, J. and Y. Engelborghs. Tubulin polymerization in dimethyl sulfoxide. J. Biol. Chem. 257, 5367-5371, 1982

45. Sakai, H., S. Shomoda and Y. Нiramoto. Mass isolation of mitotic apparatus using a glycerol/Mg2+/Triton X-100 medium. Exp. Cell Res. 104, 457-461, 1977

46. Salmon, E.D., R.J. Leslie, W.M. Saxton, M.L. Karow and J.R. McIntosh. Spindle microtubule dynamics in sea urchin embryos. J. Cell Biol. 99, 2165-2174, 1984

47. SAto, H. and J. BRYAN. The thermodynamics of molecular association in the mitotic spindle with or without heavy water $\left(\mathrm{D}_{2} \mathrm{O}\right)$. Zool. Sci., 5, 623-638, 1988

48. SAto, H. The mitotic spindle. In “Aging gamates” Blandau, J. ed. S. Karger AG, Basel, pp. 1949, 1975

49. Sato, H., G.W. Ellis and S. Inoue. Microtubular origin of mitotic spindle form birefringence. Demonstration of the applicability of Wiener's equation. J. Cell Biol. 67, 501-517, 1975

50. Sato, H., Y. OhNuKI and Y. Sato. Assembly and disassembly of the mitotic spindle. In "Cell motility. Molecules and organization” Hatano, S., Ishikawa, H. \& Sato, H. eds., Univ. Tokyo Press, Tokyo, pp. 551-568, 1979

51. SAто, H. Role of spindle microtubules for the anaphase chromosome movements in fertilized sea urchin eggs. Cell Differentiation 11, 345-348, 1982

52. Sato, H., T. Kato, T.C. Takahashi and T. Ito. Analysis of $\mathrm{D}_{2} \mathrm{O}$ effect on in vivo and in vitro tubulin polymerization and depolymerization. In "Biological functions of microtubules and related structures” Sakai, H., Mohri, H. \& Borisy, G.G. eds., Academic Press, New York, pp. 211-226, 1982

53. Sato, H., А. Коваy ashi and T.J. Ітон. The mitotic arresters: Molecular probes of spindle assembly. in "Cell Motility -II. Mechanism and Regulation", eds. H. Ishikawa, S. Hatano and H. Sato, Univ. Tokyo Press, Tokyo, pp. 357-370, 1985

54. Sato, Y. ANd H. Sato. Effect of the mitotic arrester on the spindle assembly in dividing endosperm cells of Haemanthus katharinae. Cell Struct. Funct. 10, 540, 1985

55. Schatten, H., G. Schatten, D. Mazia, R. Balczon and C. Simerly. Behavior of centrosomes during fertilization and cell division in mouse oocytes and in sea urchin eggs. Proc. Natl. Acad. Sci. $U S A, 83,105-109,1986$

56. Schiff, P.B., J. Fant and S.B. Horwitz. Promotion of microtubule assembly in vitro by Taxol. Nature 277, 665-667, 1979

57. StEPhens, R.E. A thermodynamic analysis of mitotic spindle equilibrium at active metaphase. $J$. Cell Biol. 57, 133-147, 1973

58. Strahs, K.R. and H. Sato. Potentiation of vinblastine crystal formation in vivo by puromysin and colcemid. Exp. Cell Res. 80, 10-14, 1973

59. TAKAHASHi, T.C. and H. Sato. Thermodynamic analysis of the effect of $\mathrm{D}_{2} \mathrm{O}$ on mitotic spindles in developing sea urchin eggs. Cell. Struct. Funct. 7, 349-357, 1982

60. TAKAHASH, T.C. and H. Sato. Effects of heavy water $\left(\mathrm{D}_{2} \mathrm{O}\right)$ on the length of the mitotic period in developing sea urchin eggs. Cell Struct. Funct. 8, 357-365, 1984a

61. TAKAHASHI, T.C. and H. SAto. Yields of tubulin paracrystals, vinblastine-crystals, induced in unfertilized and fertilized sea urchin eggs in the presence of $\mathrm{D}_{2} \mathrm{O}$. Cell Struct. Funct. 9, 45-52, 1984b 
62. Tanida, S., T. Hasegawa and E. Higashide. Macbecin I and II, New antitumor antibiotics. $J$. Antibiotics 33, 199-204, 1980

63. Uratani, Y. Polymerization of Salmonella flagellin in water and deuterium oxide media. $J$. Biochem. 75, 1143-1151, 1974

64. Wani, M.C., H.L. TaYlor, M.E. Wall, P. Coggon and A.T. McPhail. Plant antitumor agents. VI. The isolation and structure of Taxol, a novel antieukemic and antitumor agent from Taxas brevifolia. J. Am. Chem. Soc. 93, 2325-2327, 1971

65. Weingarten, M.D., A.H. Lockwood, S.-Y. Hwo and M.W. Kirschner. A protein factor essential for microtubule assembly. Proc. Natl. Acad. Sci. USA, 72, 1858-1862, 1975

66. WIENER, O. Die Theorie des Mischkörpers für des Feld der stationären Strömung. Abh. Sächs. Ges. Akad. Wiss., Math-Phys. Kl. No. 6, 32, 509-604, 1912

(Received for publication, December 20, 1988) 